\title{
The Extension of the LeiCNS-PK3.0 Model in Combination with the "Handshake" Approach to Understand Brain Tumor Pathophysiology
}

\author{
Makoto Hirasawa $^{1}$ D $\cdot$ Mohammed A. A. Saleh ${ }^{1}$ - Elizabeth C. M. de Lange ${ }^{1}$
}

Received: 11 September 2021 / Accepted: 10 December 2021 / Published online: 7 March 2022

(c) The Author(s) 2022

\begin{abstract}
Micrometastatic brain tumor cells, which cause recurrence of malignant brain tumors, are often protected by the intact blood-brain barrier (BBB). Therefore, it is essential to deliver effective drugs across not only the disrupted blood-tumor barrier (BTB) but also the intact BBB to effectively treat malignant brain tumors. Our aim is to predict pharmacokinetic (PK) profiles in brain tumor regions with the disrupted BTB and the intact BBB to support the successful drug development for malignant brain tumors. LeiCNS-PK3.0, a comprehensive central nervous system (CNS) physiologically based pharmacokinetic (PBPK) model, was extended to incorporate brain tumor compartments. Most pathophysiological parameters of brain tumors were obtained from literature and two missing parameters of the BTB, paracellular pore size and expression level of active transporters, were estimated by fitting existing data, like a "handshake". Simultaneous predictions were made for PK profiles in extracellular fluids (ECF) of brain tumors and normal-appearing brain and validated on existing data for six small molecule anticancer drugs. The LeiCNS-tumor model predicted ECF PK profiles in brain tumor as well as normal-appearing brain in rat brain tumor models and high-grade glioma patients within twofold error for most data points, in combination with estimated paracellular pore size of the BTB and active efflux clearance at the BTB. Our model demonstrated a potential to predict PK profiles of small molecule drugs in brain tumors, for which quantitative information on pathophysiological alterations is available, and contribute to the efficient and successful drug development for malignant brain tumors.
\end{abstract}

KEY WORDS blood-tumor barrier · brain tumors · physiologically based pharmacokinetic model $\cdot$ tumor pathophysiology

\section{Introduction}

Glioblastomas (GBM) are the most common and most malignant brain tumors, with a 5-year relative survival of only $6.8 \%$ (1). In spite of many efforts to develop novel therapeutic agents, only 4 drugs (temozolomide, lomustine, carmustine and bevacizumab) and 1 device (tumor treatment fields) are currently available for the treatment of high-grade gliomas (HGG) including GBM (2), and the prognosis remains poor with inevitable tumor recurrence (3). One of the major causes of treatment failure is attributable

Makoto Hirasawa

m.hirasawa@lacdr.leidenuniv.nl

1 Division of Systems Biomedicine and Pharmacology, Leiden Academic Centre for Drug Research, Leiden University, Einsteinweg 55, 2333 CC Leiden, The Netherlands to the insufficient drug exposure to tumor tissue, due to the presence of the blood-brain barrier (BBB) (3). The BBB is composed of specialized brain microvascular endothelial cells (BMEC) surrounded by pericytes, basement membrane and astrocyte end-feet, and strictly limits the delivery of drugs from blood into brain parenchyma as well as regulates homeostasis of the central nervous system (CNS) (4).

Malignant brain tumors are known to disrupt the integrity of the BBB and widen the inter-endothelial tight junctions during diseases progression, which is referred to as the blood-tumor barrier (BTB) $(5,6)$. The intratumoral microvasculature (MV) with the disrupted BTB, especially in HGG, are believed to be generally leakier than healthy brain MV with the intact BBB, as demonstrated by the intratumoral accumulation of brain impenetrant contrast agents in essentially all GBM (7). However, clinical evidence demonstrated that there is also a clinically significant tumor burden with an intact BBB in all GBM $(3,8,9)$. Several preclinical studies have also shown that 
the BTB displays highly heterogeneous permeability not only in animal glioma models but also in animal brain metastasis models (10-12). These findings indicate that it is essential to deliver pharmacologically active drugs across not only the disrupted BTB but also the intact BBB to effectively treat HGG, while many drugs with poor BBB penetration have been tested and failed in clinical trials (6). Therefore, the prediction of pharmacokinetic (PK) profiles in tumor tissues in both regions is crucially important for the successful drug development for HGG. In addition, since novel drug candidates are selected using experimental animal brain tumor models during the drug discovery process, it is of great significance to quantitatively understand and describe the impact of pathophysiological alterations in each animal model on tumor drug exposure for an appropriate understanding of PK-pharmacodynamics (PD) relationships and the selection of right candidates for clinical trials which are likely to reach the target site at therapeutic levels to show the desired pharmacological responses.

Our group recently developed a comprehensive physiologically based pharmacokinetic (PBPK) model, "LeiCNS-PK3.0", for the prediction of CNS PK profiles of small molecule drugs with a wide range of physicochemical properties and demonstrated the drug dependent impact of altered physiological conditions on unbound PK profiles in multiple physiological CNS compartments, including brain extracellular fluid (ECF), intracellular fluid (ICF) and cerebrospinal fluid (CSF) $(13,14)$.

In the present study, we extended the LeiCNS-PK3.0 model to predict unbound PK profiles in brain tumor tissue simultaneously with those in normal-appearing brain tissue, by adding brain tumor compartments and integrating pathophysiological properties of brain tumors. Some of the pathophysiological parameters of brain tumors are, however, currently unavailable for the "bottom-up" model development, in spite of the urgent demand for the development of novel therapeutic agents for malignant brain tumors. In this study, we used the "handshake" approach, i.e., fitting existing data, to understand and estimate what pathophysiological alterations could be in brain tumors, making the most of existing data. In addition, tumor heterogeneity, especially in terms of heterogenous barrier functions of the BBB/BTB within and between tumor masses, ideally needs to be addressed in predicting drug exposure to tumor tissue. Nevertheless, firstly we used a categorical approach focusing on tumor core region and normal-appearing brain region in the present study, based on the availability of quantitative information on pathophysiological alterations.

\section{Materials and Methods}

\section{In Vivo Unbound PK Profiles}

In vivo $\mathrm{PK}$ data of six small molecule drugs including methotrexate, temozolomide, ganciclovir, gemcitabine, letrozole and cisplatin was obtained by an extensive literature search using the National Library of Medicine PubMed database with free text terms "brain tumor" OR "glioma" AND "microdialysis", considering synonyms. These drugs were selected as their plasma PK data and microdialysis (MD) data in both tumor tissue and control (healthy, sham, contralateral or non-contrastenhancing (NE)) brain tissue in rat brain tumor models or human patients are available in the same research article. In order to appropriately understand the impact of pathophysiological alterations in brain tumors on tumor PK profiles, which is the major purpose of this study, control brain PK data measured under the same conditions as tumor PK is crucially important as the "best basis" for further analysis on tumor compartments and therefore publications lacking control brain PK data were excluded. No other factors than the availability of PK data were considered in the drug selection. In addition, methotrexate data in $\mathrm{C} 6$ glioma model rats reported by Dukic et al. (15) was excluded because BBB functionality in the contralateral hemisphere of this model was likely to be already affected by the ipsilateral C6 glioma. Table I includes data references. Total drug concentrations in plasma were corrected using the fraction unbound in plasma where needed. $\mathrm{Kp}_{\mathrm{uu}, \mathrm{ECF}}$, the ratio of the unbound drug concentration in ECF to that in plasma at steady state, was either available from literature or calculated using the reported ratio of area under the unbound concentration-time curve in ECF to that in plasma. It should be noted that PK profile after the administration of cisplatin was reported as that of free platinum (16) and probably includes metabolites.

\section{Addition of Brain Tumor Compartments to the LeiCNS-PK3.0 Model}

The LeiCNS-PK3.0 model consists of an empirical plasma PK model and a nine-compartment CNS model with the physiological parameters. CNS compartments include brain MV plasma, brain ICF, brain ECF, brain cell membrane and lysosomes, and four CSF compartments (lateral ventricle (LV), $3^{\text {rd }}$ and $4^{\text {th }}$ ventricle (TFV), cisterna magna (CM) and sub-arachnoid space (SAS)). More information on the model building, the physiological parameters of rat and human under healthy condition, and the associated equations can be found at $(13,27)$. Here, five compartments 
Table I Summary of in vivo PK Data and fup Collected from Literature

\begin{tabular}{|c|c|c|c|c|c|c|c|c|c|}
\hline \multirow[t]{2}{*}{ Species } & \multirow[t]{2}{*}{ Drug } & \multirow{2}{*}{$\begin{array}{l}\text { PK data } \\
\text { reference }\end{array}$} & \multicolumn{2}{|l|}{ fup } & \multicolumn{2}{|l|}{ Non-tumor brain } & \multicolumn{3}{|l|}{ Brain tumor } \\
\hline & & & Value & Reference & Brain type & $\mathrm{Kp}_{\mathrm{uu}, \mathrm{ECF}}$ & Tumor model & Tumor type & $\mathrm{Kp}_{\mathrm{uu}, \mathrm{ECF}}$ \\
\hline \multirow{12}{*}{$\begin{array}{l}\text { Rat brain tumor } \\
\text { models }\end{array}$} & \multirow[t]{5}{*}{ Methotrexate } & (17) & \multirow[t]{5}{*}{0.448} & \multirow[t]{5}{*}{ (19) } & Sham brain & 0.114 & RG-2 & Rat glioma & 0.105 \\
\hline & & \multirow[t]{3}{*}{ (18) } & & & Healthy brain & 0.118 & \multirow[t]{3}{*}{ R-6 } & \multirow{3}{*}{$\begin{array}{l}\text { Rat rhabdomyosar- } \\
\text { coma }\end{array}$} & \multirow[t]{3}{*}{0.250} \\
\hline & & & & & Sham brain & 0.114 & & & \\
\hline & & & & & $\begin{array}{l}\text { Contralateral hemi- } \\
\text { sphere }\end{array}$ & 0.096 & & & \\
\hline & & (15) & & & $\begin{array}{l}\text { Contralateral hemi- } \\
\text { sphere }\end{array}$ & 0.00527 & CNS1 & Rat glioma & 0.123 \\
\hline & Temozolomide & (20) & 0.85 & $(21)$ & $\begin{array}{l}\text { Contralateral hemi- } \\
\text { sphere }\end{array}$ & 0.262 & SF188/V+ & Human glioma & 0.227 \\
\hline & Ganciclovir & $(22)$ & - & - & $\begin{array}{l}\text { Contralateral hemi- } \\
\text { sphere }\end{array}$ & 0.269 & BT4C & Rat glioma & 0.785 \\
\hline & \multirow[t]{2}{*}{ Gemcitabine } & \multirow[t]{2}{*}{ (23) } & \multirow[t]{2}{*}{-} & \multirow[t]{2}{*}{-} & Healthy brain & 0.065 & \multirow[t]{2}{*}{ C6 } & \multirow[t]{2}{*}{ Rat glioma } & \multirow[t]{2}{*}{0.186} \\
\hline & & & & & $\begin{array}{l}\text { Contralateral hemi- } \\
\text { sphere }\end{array}$ & 0.085 & & & \\
\hline & \multirow[t]{2}{*}{ Letrozole } & \multirow[t]{2}{*}{ (24) } & \multirow[t]{2}{*}{0.38} & \multirow[t]{2}{*}{ (24) } & Healthy brain & 0.786 & \multirow[t]{2}{*}{ C6 } & \multirow[t]{2}{*}{ Rat glioma } & \multirow[t]{2}{*}{1.40} \\
\hline & & & & & $\begin{array}{l}\text { Contralateral hemi- } \\
\text { sphere }\end{array}$ & 0.678 & & & \\
\hline & Cisplatin & (16) & - & - & $\begin{array}{l}\text { Contralateral hemi- } \\
\text { sphere }\end{array}$ & 0.04 & $9 \mathrm{~L}$ & Rat gliosarcoma & 0.69 \\
\hline $\begin{array}{l}\text { Human brain tumor } \\
\text { patients }\end{array}$ & Methotrexate $^{\mathrm{a}}$ & $(25)$ & 0.677 & (26) & $\begin{array}{l}\text { Non-contrast-enhanc- } \\
\text { ing brain region }\end{array}$ & $\begin{array}{l}0.0473(C) \\
0.139(D)\end{array}$ & - & High-grade glioma & $\begin{array}{l}0.415(\mathrm{~A}) \\
0.451(\mathrm{~B})\end{array}$ \\
\hline
\end{tabular}

ECF: brain extracellular fluid; fup: fraction unbound in plasma; $\mathrm{Kp}_{\mathrm{uu}, \mathrm{ECF}}$ : the ratio of the unbound drug concentration in $\mathrm{ECF}$ to that in plasma at steady state

${ }^{a}$ Parentheses represent patient ID

of brain tumor (MV, ICF, ECF, tumor cell membrane and lysosomes) having the same structure as the healthy brain model were added between plasma and LV compartments. Because the spatial information on tumor site within the whole brain in each individual is not available, no transport between tumor ECF and healthy brain ECF was assumed. Figure 1 displays the model structure of the LeiCNS-PK3.0 model with brain tumor compartments (hereinafter referred to as the "LeiCNS-tumor" model).

\section{Data Analysis and Software}

Parameter estimation was performed using NONMEM version 7.4.3 (ICON, Dublin, Ireland) (28). General data analysis, visualization and LeiCNS-PK3.0 simulations were performed using $\mathrm{R}$ version 4.0 .3 (29). LeiCNS-PK3.0 simulations were performed using RxODE package version 0.9.2.1 (30), using the LSODA (Livermore Solver for Ordinary Differential Equations) Fortran package. WebPlotDigitizer version 4.4 (https://apps.automeris.io/wpd/) was used to extract data from literature.

\section{Empirical Plasma PK Models}

Plasma PK models of unbound drugs were developed using in vivo data with a non-linear mixed effects modeling approach, where one- or two- compartment models were evaluated. For ganciclovir, a lag time was tested considering the delayed onset of absorption after intraperitoneal administration (22). Interindividual variability (IIV) was tested for methotrexate PK data in rats reported by de Lange et al. (18) using exponential models for clearance (CL) and volume of distribution of central compartment. Residual unexplained variability (RUV) was included using either proportional or combined proportional/additive error models. The final model was selected based on the objective function value and visual predictive check (VPC) plots to compare the model fit to unbound $\mathrm{PK}$ profiles in plasma.

\section{Drug-Specific Physicochemical Parameters}

The physicochemical parameters of six drugs including molecular weight, the ionization constants of the strongest acidic group $\left(\mathrm{pK}_{\mathrm{a}}\right)$ and the strongest basic group $\left(\mathrm{pK}_{\mathrm{b}}\right)$ that are the most significant parameters determining the proportion of charged and uncharged molecule at a given $\mathrm{pH}$, and lipophilicity $\left(\log \mathrm{P}_{\mathrm{o} / \mathrm{w}}\right)$ were collected from DrugBank version 5.1.7 (31) and are listed in Table II. Experimental $\log \mathrm{P}_{\mathrm{o} / \mathrm{w}}$ values were used, while calculated $\mathrm{pK}_{\mathrm{a}} /$ $\mathrm{pK}_{\mathrm{b}}$ values by the MARVIN method provided by CHEMAXON (32) were used. Parameters of cisplatin were used 


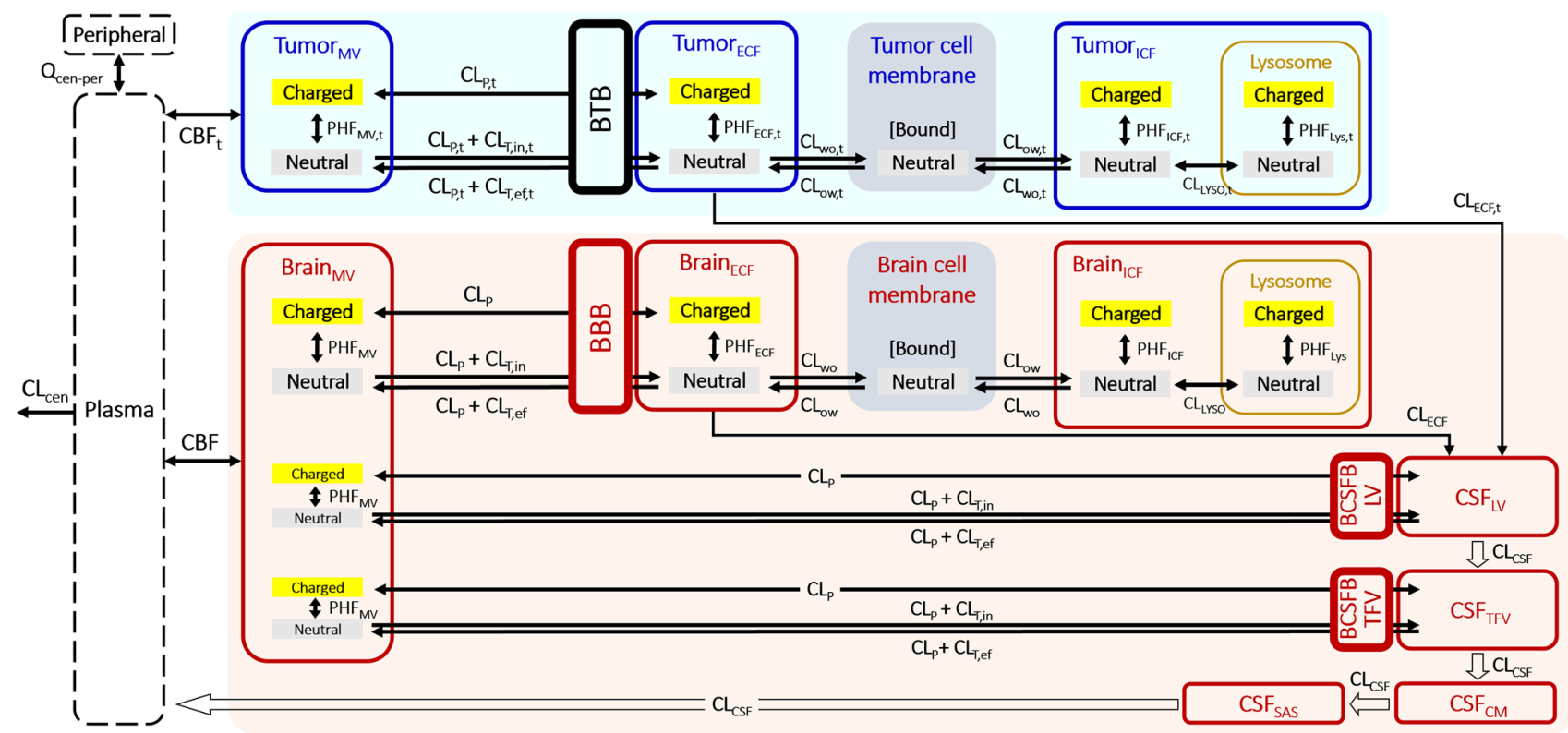

Fig. 1 Structure of the LeiCNS-tumor model. Five tumor compartments (highlighted in blue) were added between plasma and CSF LV $_{\text {compart- }}$ ments of the LeiCNS-PK3.0 model. Descriptions with subscript "t" represent processes in brain tumor compartments. [Barriers] BBB: blood brain barrier; BCSFB: blood CSF barrier; BTB: blood tumor barrier; [Compartments] CM: cisterna magna; CSF: cerebrospinal fluid; ECF: brain extracellular fluid; ICF: brain intracellular fluid; LV: lateral ventricles; MV: brain microvasculature; SAS: subarachnoid space; TFV: 3rd \& 4th ventricles; [Factors] PHF: $\mathrm{pH}$ factor; [Flows] CBF: cerebral blood flow; $\mathrm{CL}_{\text {cen }}$ : central clearance; $\mathrm{CL}_{\mathrm{ECF}}$ : $\mathrm{ECF}_{\mathrm{Culk}}$ flow; $\mathrm{CL}_{\mathrm{CSF}}$ : $\mathrm{CSF}$ flow; $\mathrm{CL}_{\mathrm{LYSO}}$ : transmembrane clearance of lysosomes; $\mathrm{CL}_{\mathrm{ow}}$ : lipid-to-water clearance; $\mathrm{CL}_{\mathrm{wo}}$ : water-to-lipid clearance; $\mathrm{CL}_{\mathrm{p}}$ : paracellular transport clearance; $\mathrm{CL}_{\mathrm{T}, \mathrm{ef}}$ : efflux transcellular clearance; $\mathrm{CL}_{\mathrm{T}, \mathrm{in}}$ : influx transcellular clearance.

as representative parameters for all the cisplatin-derived free platinum compounds, possibly including cisplatin and its metabolites, existing in rats after the administration of cisplatin. Asymmetry factors (AF) were calculated from $\mathrm{Kp}_{\mathrm{uu}, \mathrm{ECF}}$ in control brain using the LeiCNS-PK3.0 equations at steady state as previously reported (13).

\section{Pathophysiological Parameters of Brain Tumors}

Quantitative information on pathophysiological alterations in brain tumor tissues, including tumor blood flow, volume fractions of MV and ECF, extracellular and intracellular $\mathrm{pH}$, in experimental animal models as well as human patients was obtained by an extensive literature search using the National Library of Medicine PubMed database with free text terms "brain tumor model name or brain tumor type" AND "parameter name", considering synonyms. When multiple values were found, the mean value was used for each animal model or tumor type. When no information was found for a certain animal model or tumor type, the mean value of the same or similar tumor types was used. For tumor blood flow and volume fraction of MV, for which parameter values in control (healthy or contralateral) brain tissues are often reported in the same literature, relative values in tumor to control brain were calculated and then multiplied by the representative healthy brain values reported by Saleh $e t$ al. (13) to calculate the representative tumor parameters. In case of the lack of information, the same values as healthy brain were assumed for parameters below: $\mathrm{pH}$ in MV and lysosomes, volume fractions of phospholipids and lysosomes,
Table II Drug-Specific Physicochemical Parameters of Six Small Molecule Anticancer Drugs Included in this Study

\begin{tabular}{llllll}
\hline Drug & Molecular weight & Charge class & $\begin{array}{l}\text { Strongest } \\
\text { acidic } \mathrm{pK}_{\mathrm{a}}\end{array}$ & $\begin{array}{l}\text { Strongest } \\
\text { basic } \mathrm{pK}_{\mathrm{b}}\end{array}$ & $\operatorname{logP}_{\mathrm{o} / \mathrm{w}}$ \\
\hline Methotrexate & 454.45 & Acid & 3.41 & 2.81 & -1.85 \\
Temozolomide & 194.15 & Neutral & 10.51 & -3.6 & -1.153 \\
Ganciclovir & 255.23 & Neutral & 10.16 & 1.76 & -1.66 \\
Gemcitabine & 263.20 & Neutral & 11.52 & 3.65 & -1.4 \\
Letrozole & 285.30 & Neutral & NA & 2.17 & 2.5 \\
Cisplatin & 300.05 & Neutral & NA & NA & -2.19 \\
\hline
\end{tabular}

NA: not applicable 
and ECF bulk flow per brain/tumor volume. Surface area of the tumor BTB was estimated by multiplying that of the healthy brain BBB by the ratio of MV volumes between tumor and healthy brain. The sphere radius of tumor cells was assumed to be equal to that of healthy brain parenchymal cells (13) both in experimental animal models and human patients based on literature information $(33,34)$.

\section{Estimation of Correction Factors for Paracellular Permeability Across the Control Brain BBB}

Although the LeiCNS-PK3.0 model predicted control brain ECF PK profiles of the six drugs in this study within twofold error for most data points (Supplementary Fig.S1) as reported (13), there was a tendency to overestimate the maximum concentrations $\left(\mathrm{C}_{\max }\right)$ of several drugs in control brain ECF and the elimination rate of methotrexate from ECF compartment. The main objective of this study is to adequately describe the impact of pathophysiological alterations on tumor PK profiles and to that end ECF PK profiles in control brain need to be described as accurately as possible, as the "best basis". By the single parameter sensitivity analyses of $\mathrm{pH}$ values, fluid flows, and ECF volume, we found that reduction of paracellular permeability (PPA) across the BBB gave better descriptions of control brain ECF PK profiles for some drugs, while the impact of changing other parameters was negligible. Therefore, we corrected PPA across the control brain BBB to obtain the "best basis" for an appropriate understanding of the impact of pathophysiological alterations on tumor PK. PPA correction factor of each drug in each animal model or patient was estimated by fitting ECF PK data in control brain (healthy, sham or contralateral brain in rat brain tumor models and NE brain region in human patients) to the LeiCNS-PK3.0 model.

\section{Estimation of Fold Changes of Paracellular Pore Size of the BTB and Active Efflux CL at the BTB Compared with the Control Brain BBB by the "Handshake" Approach}

The LeiCNS-PK3.0 model calculates PPA of each drug across the BBB and blood-CSF barrier (BCSFB) based on the aqueous diffusivity coefficient of the drug, the width of the BBB/BCSFB and the surface area of paracellular pore $(13,27)$. Considering the highly hydrophilic nature of contrast agents used to demonstrate the disruption of the BTB in $\mathrm{HGG}$, it is quite reasonable to attribute their intratumoral accumulation to the increase of their PPA across the BTB compared with the healthy BBB, i.e., opening of paracellular pore of the BTB $(7,8)$. However, literature information on paracellular pore size of the BTB is very limited and reported values largely vary between literature for animal brain tumor models (35-37), whereas no quantitative information is available for human brain tumor patients. In addition, no quantitative information is available on the expression levels or activities of active transporters at the BTB in animal brain tumor models. For human patients, recent studies using liquid chromatography with tandem mass spectrometry (LC-MS/MS) -based quantitative targeted proteomics demonstrated significant reduction of $\mathrm{ABCB} 1$ and $\mathrm{ABCG} 2$ protein abundances in isolated $\mathrm{MV}$ of GBM and brain metastases compared with non-cancerous cerebral cortex $(38,39)$. Taken together, pathophysiological information on paracellular pore size of the BTB and active transporter functions at the BTB, both of which are essential in predicting tumor ECF PK profiles by our model, is too limited to perform the "bottom-up" model development, especially for animal brain tumor models. To address the scarce pathophysiological information, we selected to estimate these two parameters of the BTB by fitting existing data to the LeiCNS-tumor model integrated with other available parameters, like a "handshake" with one hand (existing PK data) and the other hand (the model) settling into the best place. Both parameters, as fold changes from those in the control brain BBB, were simultaneously estimated.

\section{Model Evaluation}

Model performance was evaluated by the comparison of predicted PK profiles with the measured ones in plasma, control brain ECF, and brain tumor ECF, where the median and $95 \%$ prediction interval of 200 model simulations were compared to in vivo measured unbound PK profiles. The model simulations accounted for IIV and RUV of the plasma PK model, as described above. The relevant $\eta$ of IIV and $\varepsilon$ of RUV were randomly sampled from a normal distribution with a mean of 0 and a variance of $\omega^{2}$ and $\sigma^{2}$, respectively, and transformed as required.

Next, prediction errors were calculated using the individual measured drug concentrations and their corresponding time-matched simulated median. Relative accuracy error of a given drug $\left(\mathrm{RA}_{\mathrm{drug}}\right)$ at a given compartment was calculated as follows:

$R A_{\text {drug }}=\frac{1}{M} \sum_{i=1}^{N} \sum_{j=1}^{m} \log _{10}\left(\frac{M e d P_{i, j}}{\operatorname{Obs}_{i, j}}\right)$

$M=\sum_{i=1}^{N} m$

where $\operatorname{Obs}_{i, j}$ is $j^{\text {th }}$ observation of the $i^{\text {th }}$ individual; $\operatorname{MedP}_{i, j}$ is the median value of the 200 simulations corresponding to $\mathrm{Obs}_{\mathrm{i}, \mathrm{j}}$; $\mathrm{M}$ is the total number of observations of all individuals; $\mathrm{m}$ is the number of observations of the $\mathrm{i}^{\text {th }}$ individual; and $\mathrm{N}$ is the total number of individuals. 


\section{Results}

\section{Empirical Plasma PK Models}

The empirical plasma PK parameters in rat brain tumor models and human brain tumor patients are listed in Table III. The PK models accurately described the observed unbound PK profiles in plasma as shown in Fig. 2 (green lines and dots). For ganciclovir, introduction of a lag time clearly improved the description of its plasma PK profile, especially $\mathrm{C}_{\max }$ and the time taken to reach $\mathrm{C}_{\max }\left(\mathrm{T}_{\max }\right)$. Plasma PK model of total temozolomide in SF188/V + glioma model rats was available from the literature (20).

\section{Pathophysiological Parameters of Brain Tumors}

Five pathophysiological parameters: tumor blood flow, volume fractions of $\mathrm{MV}$ and $\mathrm{ECF}$, and extracellular and intracellular $\mathrm{pH}$, in animal brain tumor models and human brain tumors were collected from literature and are summarized in Fig. 3 including parameter values in animal models and tumor types that are not analyzed in this study. Parameter values applied to tumor compartments in this study are summarized in Table IV. Tumor/cerebral blood flow and volume fractions of MV and ECF were all higher in contrast-enhancing (CE) region of HGG than healthy human brain, low-grade gliomas (LGG), and NE region of HGG. In contrast, those values in experimental animal brain tumor models largely varied between models. Interestingly, lower extracellular $\mathrm{pH}$ and higher intracellular $\mathrm{pH}$ were consistent in all human brain tumors and tumor core of animal brain tumor models.

\section{Estimation of Correction Factors for PPA Across the Control Brain BBB}

Estimated PPA correction factor of each drug is listed in Table $\mathrm{V}$ and simulated versus observed ECF PK profiles in control brain after PPA correction are shown in Fig. 2 and Supplementary Fig.S1 (red dashed lines and red dots, respectively). Reduction of PPA improved the description of control brain ECF PK profiles, especially $\mathrm{C}_{\max }$ and $\mathrm{T}_{\max }$, except for letrozole and cisplatin. These PPA correction factors were applied to the control brain model to obtain the "best basis" for further analyses on tumor compartments except for letrozole and cisplatin, for which no PPA reduction was applied (correction factor $=1$ ). Analysis of ECF PK data of methotrexate in NE region of patient $D(25)$ indicated that no active efflux transport at the BBB is involved and drug elimination from ECF compartment mostly relies on ECF bulk flow (Supplementary Table S1), indicating the $\mathrm{BBB}$ function in NE region of patient $\mathrm{D}$ may be altered already. Therefore, we selected PK data in NE region of patient $\mathrm{C}$ as control brain data and estimated PPA correction factor in patient $\mathrm{C}$ was applied to obtain the "best basis" for further analyses of CE regions in patients A and B.

\section{Estimation of Fold Changes of Paracellular Pore Size of the BTB and Active Efflux CL at the BTB Compared with the Control Brain BBB}

Estimated fold changes of paracellular pore size of the BTB and active efflux CL at the BTB over the control brain BBB of each drug in each animal brain tumor model or HGG patient are listed in Table VI. Estimated fold change of paracellular pore size ranged from 0.172 to 49.1 , whereas that of active efflux CL ranged from -1.17 to 7.81 in animal models. In human patients, fold changes of both parameters were estimated to be higher than 1. For methotrexate in RG-2 glioma model (17), each parameter was separately estimated with the other fixed to 1 because simultaneous estimation of both parameters resulted in varied estimates depending on initial parameters. This is because the same fold changes of paracellular pore size (increase) and active BTB/BBB efflux CL (decrease) have very similar impact on PK profile, and thus parameter sets with the same ratio of these fold changes gave almost the same PK profiles. For letrozole in the C6 glioma model (24), estimated fold change of active efflux $\mathrm{CL}$ was below 0 , indicating the involvement of active influx transport as well as disappeared active efflux transport at the BTB. Out of 9 cases for six small molecule drugs tested in this study, the increase of paracellular pore size of the BTB compared with the BBB was estimated in 8 cases except for temozolomide in the SF188/V + glioma model (20), whereas the decrease of active efflux CL was estimated in 7 cases except for gemcitabine in the C6 glioma model (23) and methotrexate in human HGG patients (25).

\section{Model Evaluation}

Simulated tumor ECF PK profiles using estimated fold changes of paracellular pore size of the BTB and active efflux CL at the BTB over the control brain BBB are shown in Fig. 2 (blue dashed lines) in comparison to the observed PK profiles (blue dots). The relative accuracy errors are shown in Supplementary Fig.S2. The LeiCNS-tumor model well captured ECF PK profiles in brain tumor as well as control brain within twofold error for most data points, except for methotrexate in the R-6 rhabdomyosarcoma model (29). In this case, IIV for plasma PK parameters were not large enough to explain the interindividual difference in the observed ECF PK profiles, indicating the involvement of IIV for other factors in CNS physiology accounting for interindividual differences in brain tumor and control brain ECF PK profiles. 


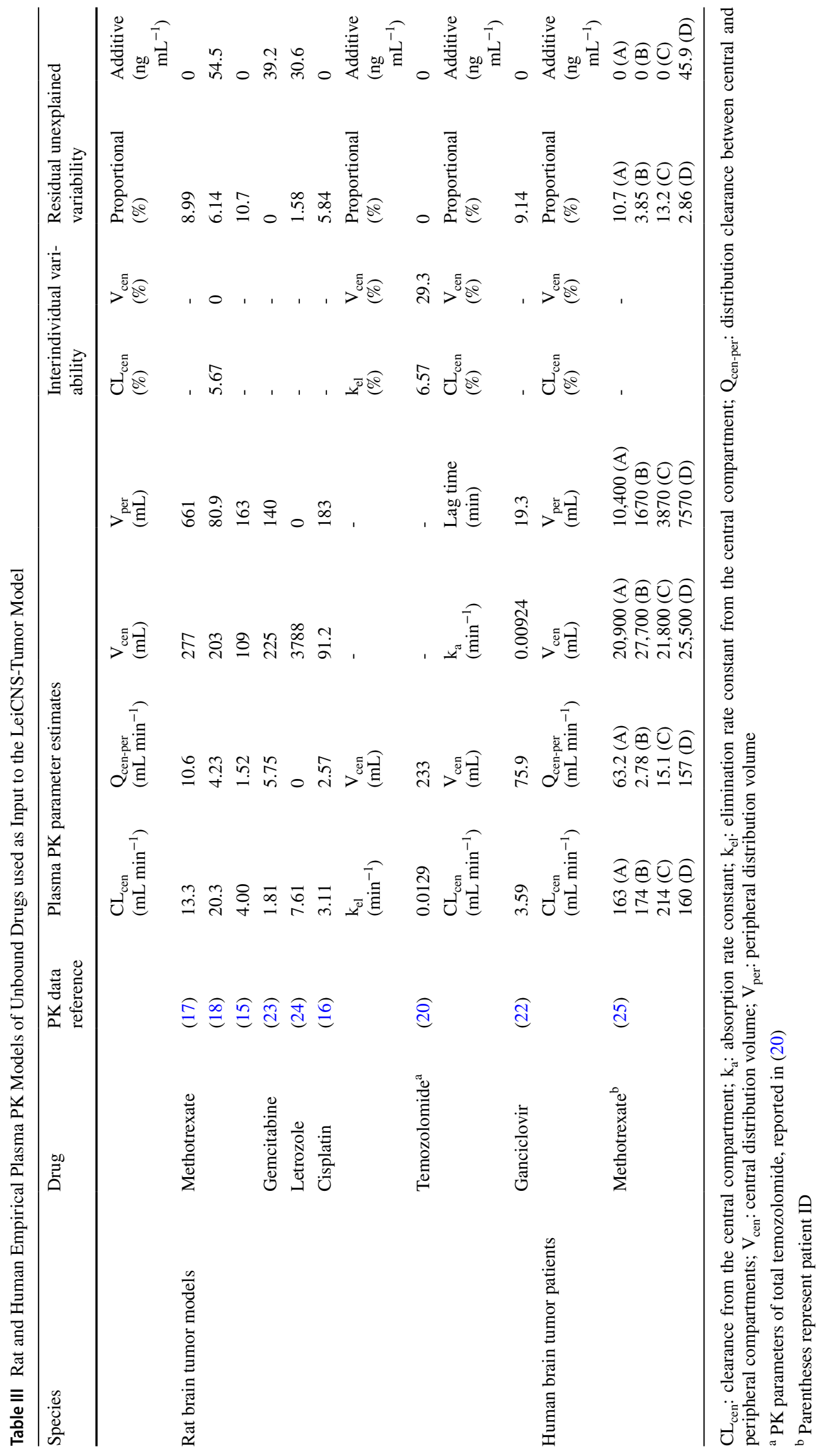


(a) Methotrexate in RG-2 glioma model

with estimated fold change of paracellular pore size
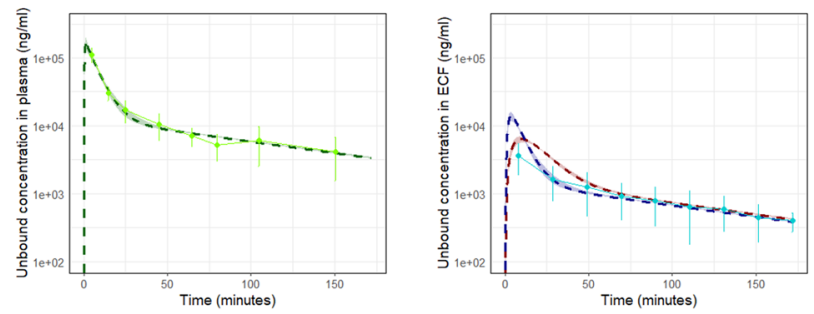

(c) Methotrexate in R-6 rhabdomyosarcoma model
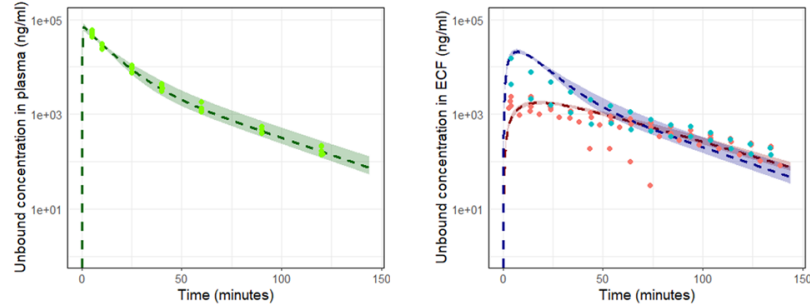

(e) Temozolomide in SF188/V+ glioma model
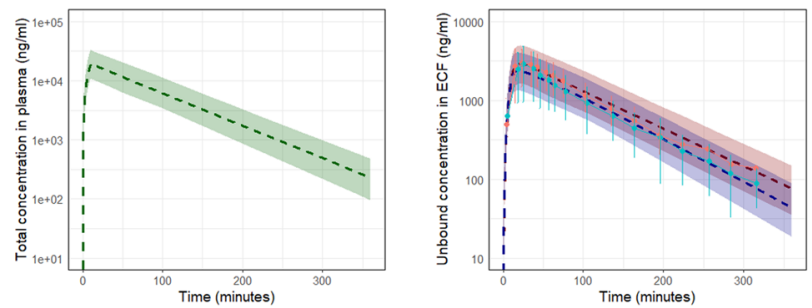

(g) Gemcitabine in C6 glioma model
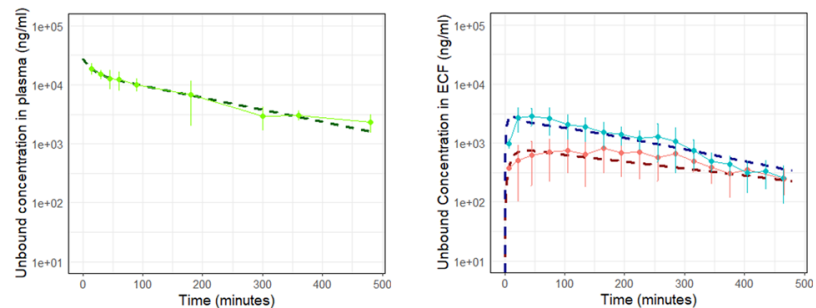

(i) Cisplatin-derived platinum in $9 \mathrm{~L}$ gliosarcoma model
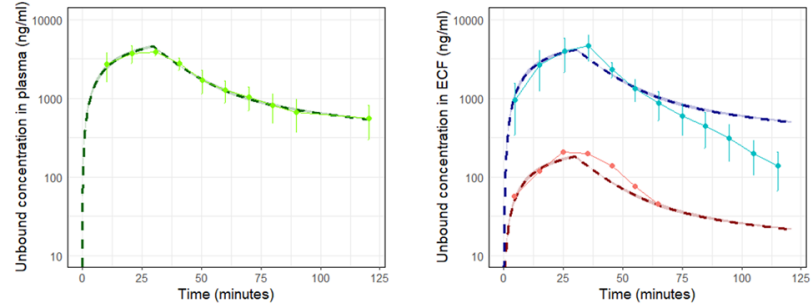

(j) Methotrexate in CE region of patient $\mathrm{A}$
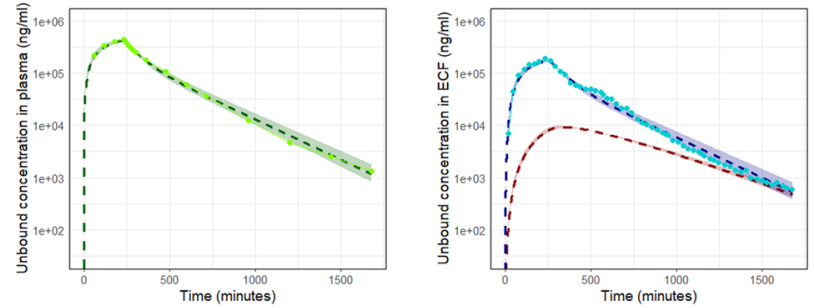

(b) Methotrexate in RG-2 glioma model

with estimated fold change of active efflux $\mathrm{CL}$
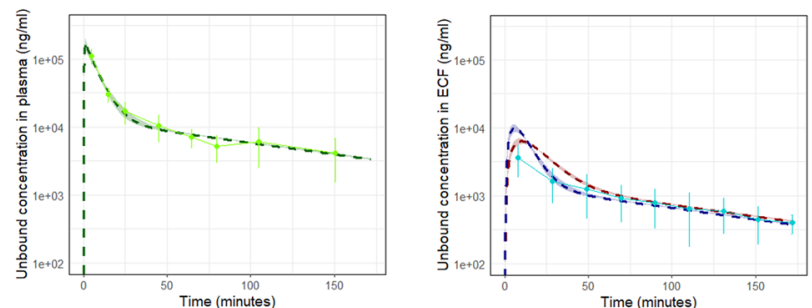

(d) Methotrexate in CNS1 glioma model
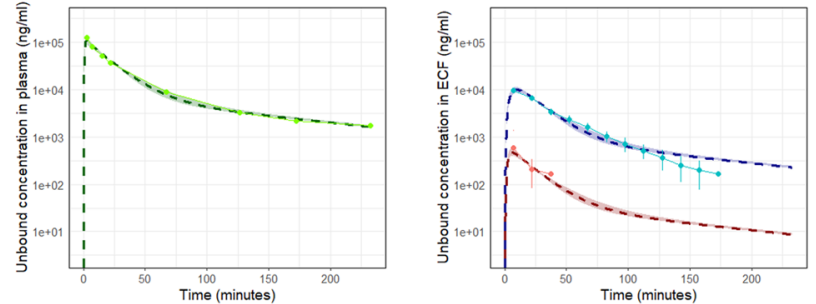

(f) Ganciclovir in BT4C glioma model
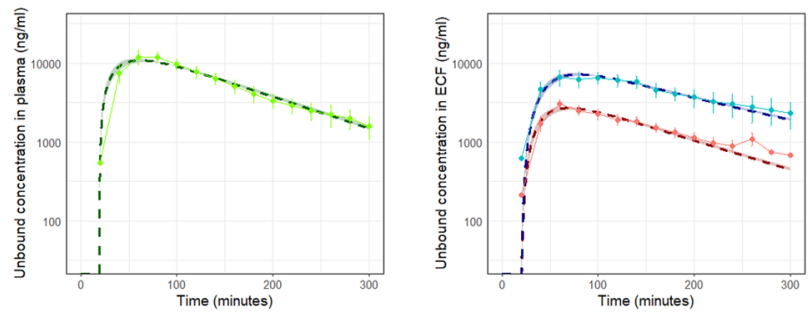

(h) Letrozole in C6 glioma model
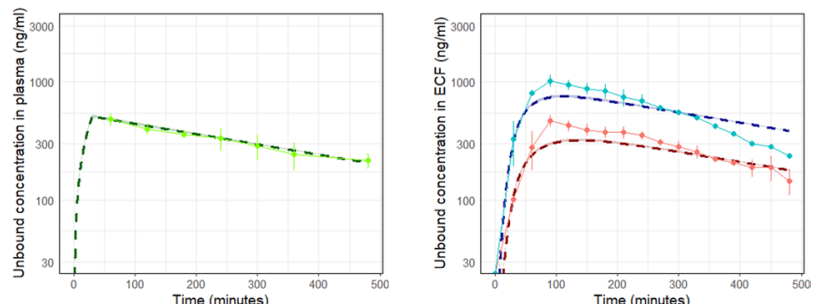

(k) Methotrexate in CE region of patient $B$
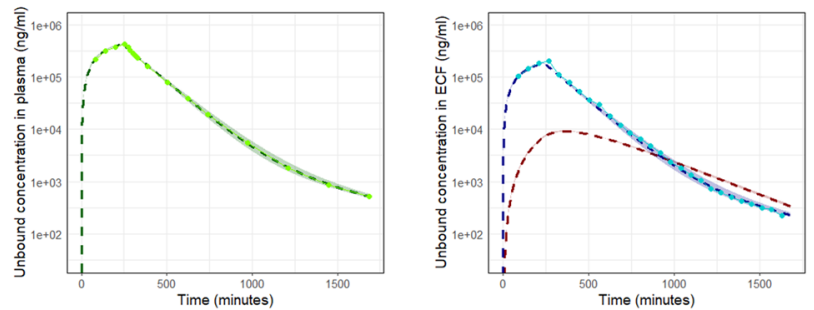
4Fig. 2 Visual predictive checks plots compared in vivo measured drug concentration (dots and solid line; mean \pm standard deviation) in plasma (green), control brain (red), and brain tumor (blue) to the median (dashed line) and 95\% prediction intervals (colored band) of 200 model simulations. Methotrexate in (a) RG-2 glioma model with estimated fold change of paracellular pore size and (b) active efflux CL, (c) R-6 rhabdomyosarcoma model and (d) CNS1 glioma model; (e) temozolomide in SF188/V + glioma model; (f) ganciclovir in BT4C glioma model; (g) gemcitabine in C6 glioma model; (h) letrozole in C6 glioma model; (i) cisplatin-derived platinum in 9L gliosarcoma model; methotrexate in (j) patient $\mathrm{A}$ and (k) patient B. CE: contrast-enhancing, ECF: brain extracellular fluid.

\section{Discussion}

Tumor recurrence in GBM patients is inevitable (3). The limited drug exposure within tumor and brain around tumor (BAT) remains a major issue limiting the long-term efficacies of anticancer agents for GBM (73). Micrometastatic tumor cells, which cause tumor recurrence, are often undetectable and unresectable, and protected by the intact BBB $(3,8)$, whereas CE region with dense tumor has the disrupted BTB (7). Such heterogeneous properties of tumor $\mathrm{MV}$, not only in terms of permeability but also perfusion, are ones of the rate-limiting factors in effective therapy of malignant brain tumors (8). Therefore, the drug candidates selected for clinical trials for malignant brain tumors should be those that are able to penetrate the intact BBB as well as the disrupted BTB. Ideally, prediction of ECF PK profiles in three (or more) different compartments; (A) tumor with the disrupted BTB, (B) tumor with the intact BBB, and $(C)$ healthy brain with the intact BBB, would be the best approach to address the tumor heterogeneity. Due to the very limited information on pathophysiological alterations in (B) tumor with the intact BBB, however, firstly we aimed to build the LeiCNS-tumor model focusing on (A) tumor with the disrupted BTB and (C) normal-appearing brain with the intact BBB in this study. If the LeiCNS-tumor

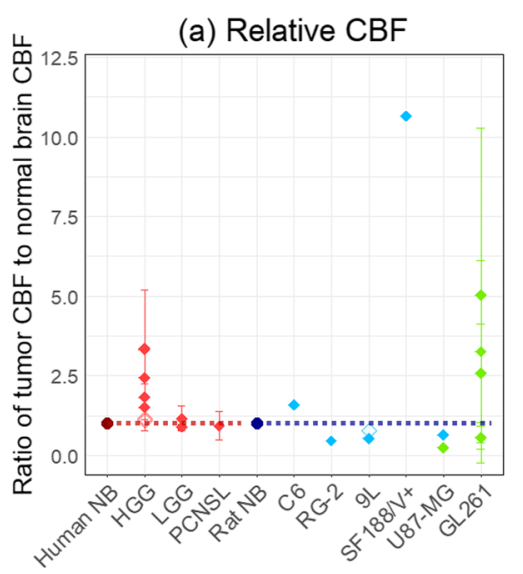

(b) Volume fraction of MV

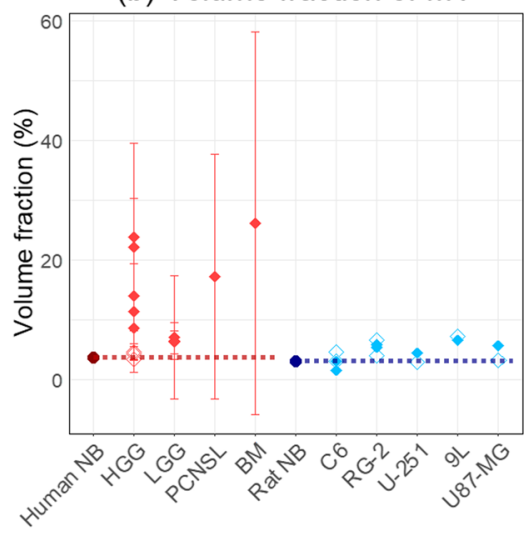

(c) Volume fraction of ECF

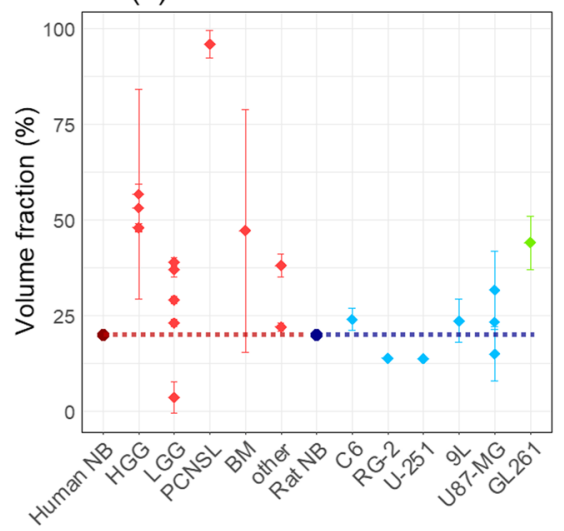

(d) Extracellular $\mathrm{pH}$

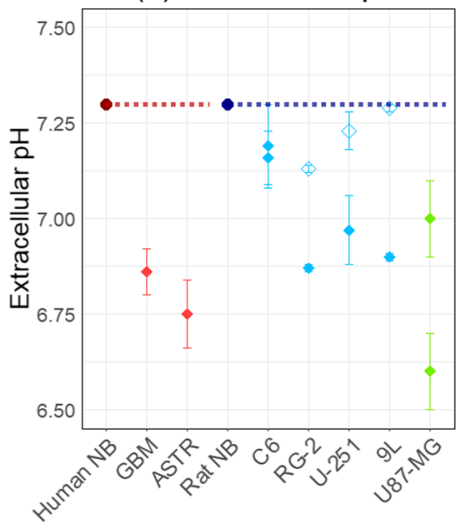

(e) Intracellular $\mathrm{pH}$

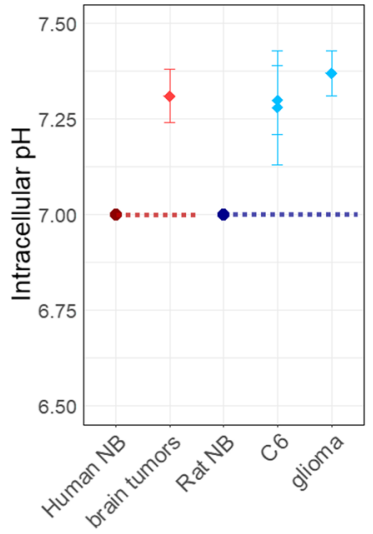

ASTR: astrocytomas

BM: brain metastases

CBF: cerebral blood flow

ECF: extracellular fluid

GBM: glioblastomas

HGG: high-grade gliomas

LGG: low-grade gliomas

$\mathrm{MV}$ : microvasculature

NB: normal brain

PCNSL: primary central nervous system lymphomas

Fig. 3 Summary of reported pathophysiological parameters in brain tumors: (a) relative CBF to healthy brain, (b) volume fraction of MV, (c) volume fraction of ECF, (d) extracellular $\mathrm{pH}$ and (e) intracellular $\mathrm{pH}$, including tumor models and tumor types that are not analyzed in this study. Each point represents mean \pm standard deviation or standard error of the mean in each literature. Values in human, rat, mouse are shown in red, cyan, and light green, respectively. Closed symbols represent tumor core (animal tumor models) or contrast-enhancing region (human patients), whereas open symbols represent peritumoral region or non-contrast-enhancing region. Dashed lines represent values of healthy brains. References: (a) (13, 40-51); (b) (13, 36, 43, 47, 48, 52-59); (c) (13, 34, 52, 55, 57, 60-64); (d) (13, 65-69); (e) (13, 65, 67, 70). 
Table IV Pathophysiological Parameters in Animal Brain Tumor Models and High-Grade Glioma Patients

\begin{tabular}{|c|c|c|c|c|c|c|c|c|}
\hline \multirow[t]{2}{*}{ Species } & \multirow{2}{*}{$\begin{array}{l}\text { Tumor model/ } \\
\text { patient ID (25) }\end{array}$} & \multirow[t]{2}{*}{ Tumor type } & \multirow{2}{*}{$\begin{array}{l}\text { Tumor volume } \\
(\mathrm{mL})\end{array}$} & \multicolumn{2}{|c|}{ Volume fractions (\%) } & \multicolumn{2}{|l|}{$\mathrm{pH}$} & \multirow{2}{*}{$\begin{array}{l}\mathrm{CBF}(\mathrm{mL} \\
\left.\min ^{-1} \mathrm{~g}^{-1}\right)\end{array}$} \\
\hline & & & & MV & $\mathrm{ECF}$ & $\mathrm{ECF}$ & ICF & \\
\hline Rat & $\begin{array}{l}\text { Healthy brain } \\
\text { (13) }\end{array}$ & - & - & 3.00 & 20.0 & 7.30 & 7.00 & 1.53 \\
\hline \multirow{9}{*}{$\begin{array}{l}\text { Rat brain tumor } \\
\text { models }\end{array}$} & C6 & Rat glioma & $0.03(15)$ & $2.25(52,53)$ & $24.0(71)$ & $7.16(65)$ & $7.28(65)$ & $2.43(40)$ \\
\hline & BT4C & Rat glioma & $0.23(41)$ & $1.67(54)$ & $19.0^{\mathrm{a}}$ & $7.02^{\mathrm{a}}$ & $7.33^{\mathrm{b}}$ & $1.14(41)$ \\
\hline & RG-2 & Rat glioma & $0.075(32)$ & $5.58(33,52)$ & $13.9(71)$ & $6.87(67)$ & $7.37^{\mathrm{c}}$ & $0.698(42)$ \\
\hline & CNS1 & Rat glioma & $0.03(15)$ & $3.92^{\mathrm{a}}$ & $19.0^{\mathrm{a}}$ & $7.02^{\mathrm{a}}$ & $7.33^{\mathrm{b}}$ & $1.56^{\mathrm{a}}$ \\
\hline & R-6 & $\begin{array}{l}\text { Rat rhabdo- } \\
\text { myosarcoma }\end{array}$ & $0.17(29)$ & $6.52^{\mathrm{d}}$ & $23.6^{\mathrm{d}}$ & $6.90^{\mathrm{d}}$ & $7.37^{\mathrm{d}}$ & $0.819^{\mathrm{d}}$ \\
\hline & $9 \mathrm{~L}$ & $\begin{array}{l}\text { Rat gliosar- } \\
\text { coma }\end{array}$ & $0.20(43)$ & $6.52(43)$ & $23.6(60)$ & $6.90(67)$ & $7.37^{\mathrm{c}}$ & $0.819(43)$ \\
\hline & U87-MG & $\begin{array}{l}\text { Human glio- } \\
\text { blastoma }\end{array}$ & - & $5.61(55,56)$ & $23.3(55,61)$ & $6.80(68)$ & - & $0.672(44,45)$ \\
\hline & SF188/V + & Human glioma & $0.12(20)$ & $20.0^{\mathrm{f}}$ & $20.9^{\mathrm{e}}$ & $6.86^{\mathrm{e}}$ & $7.33^{\mathrm{b}}$ & $16.27(46)$ \\
\hline & $\mathrm{U} 251$ & $\begin{array}{l}\text { Human glio- } \\
\text { blastoma }\end{array}$ & - & $4.40(61)$ & $13.7(62)$ & $6.97(69)$ & - & - \\
\hline Human & $\begin{array}{l}\text { Healthy brain } \\
\text { (13) }\end{array}$ & - & - & 3.67 & 20.0 & 7.30 & 7.00 & 0.527 \\
\hline \multirow[t]{3}{*}{$\begin{array}{l}\text { Human brain } \\
\text { tumor patients }\end{array}$} & A & Glioblastoma & $50(20)$ & $\begin{array}{l}14.9(47,48,57, \\
58)\end{array}$ & $54.9(57,63)$ & $6.86(66)$ & $7.31^{\mathrm{g}}$ & $1.31(47-50)$ \\
\hline & B & $\begin{array}{l}\text { Anaplastic } \\
\text { astrocytoma }\end{array}$ & $50(20)$ & $15.5(47,57,58)$ & $52.6(57,63,64)$ & 6.75 & $7.31^{\mathrm{g}}$ & $\begin{array}{l}1.17(47,49 \text {, } \\
50)\end{array}$ \\
\hline & C, D & $\begin{array}{l}\text { Anaplastic } \\
\text { oligodendro- } \\
\text { glioma }\end{array}$ & $50(20)$ & $16.2(47,57)$ & $44.3(57,63,64)$ & $6.81^{\mathrm{h}}$ & $7.31^{\mathrm{g}}$ & $\begin{array}{l}1.17(47,49 \text {, } \\
50)\end{array}$ \\
\hline
\end{tabular}

CBF: cerebral blood flow; ECF: brain extracellular fluid; ICF: brain intracellular fluid; MV: microvasculature

Parentheses represent references

a Average values of RG-2 and C6 (rat gliomas)

b Average values of C6 and "rat glioma"

c Value of "rat glioma" (67)

${ }^{\mathrm{d}}$ Values of 9L (rat gliosarcoma)

${ }^{\mathrm{e}}$ Average values of U251 and U87-MG (human gliomas)

${ }^{\mathrm{f}} 4 \times$ average value of U251 and U87-MG (human gliomas) considering its highly vascularized property (MV density in subcutaneous xenograft of SF188/V + glioma was 4 times higher than parental SF188/V- glioma (72))

g Value of "brain tumour" (66)

${ }^{\mathrm{h}}$ Average value of glioblastoma and anaplastic astrocytoma

model successfully predicts ECF PK profiles in both (A) and (C), it can be further extended to (B) and more complex heterogenous tumors when the pathophysiological information becomes available. Furthermore, some of the pathophysiological parameters of brain tumors are quite scarce even for (A) tumor with the disrupted BTB. The development of novel therapeutic agents for malignant brain tumors is an urgent matter and every possible effort to improve the possibility of success in the drug development should be made immediately, instead of waiting until enough information become available. Therefore, in this study, we used the "handshake" approach to understand and extract pathophysiological alterations in brain tumors from existing data on tumor PK.
It is generally accepted that it is the unbound drug that equilibrates over biological membranes and is able to interact with target molecules, and MD is a key technique to obtain time-dependent information on unbound drug concentration in ECF of the target tissues (74). Although intratumoral MD has been performed also in neurooncology, clinical examples are quite rare due to ethical restrictions of human brain sampling $(75,76)$. In addition, its labor-intensiveness and requirement of high technical skills make it difficult to routinely perform MD experiments during the drug discovery process even in animal brain tumor models, especially in parallel with efficacy studies. The ultimate goal of this research is to establish a comprehensive brain tumor PBPK model that can be 
Table V Summary of the Control Brain Models used as the "Best Basis" for the Analyses on Tumor Compartments

\begin{tabular}{|c|c|c|c|c|c|c|}
\hline Species & Drug & $\begin{array}{l}\text { PK data } \\
\text { reference }\end{array}$ & Control brain used as the "best basis" & $\begin{array}{l}\text { PPA correc- } \\
\text { tion factor } \\
\text { (fold- } \\
\text { decrease) }\end{array}$ & $\mathrm{AF}_{\mathrm{in}, \mathrm{ECF}}{ }^{\mathrm{b}}$ & $\mathrm{AF}_{\text {out,ECF }}{ }^{\mathrm{b}}$ \\
\hline \multirow[t]{8}{*}{ Rat brain tumor models } & \multirow[t]{3}{*}{ Methotrexate } & $(17)$ & Sham brain & 14.0 & 1 & $4.18 \mathrm{E}+06$ \\
\hline & & $(18)$ & Healthy brain & 36.9 & 1 & $1.50 \mathrm{E}+06$ \\
\hline & & (15) & Contralateral hemisphere & 49.8 & 1 & $2.87 \mathrm{E}+07$ \\
\hline & Temozolomide & $(20)$ & Contralateral hemisphere & 5.54 & 1 & 166 \\
\hline & Ganciclovir & $(22)$ & Contralateral hemisphere & 4.45 & 1 & 518 \\
\hline & Gemcitabine & (23) & Healthy brain & 80.1 & 1 & 74.2 \\
\hline & Letrozole & (24) & Healthy brain & $0.573^{\mathrm{c}}$ & $1^{\mathrm{d}}$ & $1.30^{\mathrm{d}}$ \\
\hline & Cisplatin & (16) & Contralateral hemisphere & $3.70^{\mathrm{c}}$ & $1^{\mathrm{d}}$ & $5.93 \mathrm{E}+04^{\mathrm{d}}$ \\
\hline Human brain tumor patients & Methotrexate & $(25)$ & Non-contrast-enhancing region & $892^{\mathrm{e}}$ & $1^{\mathrm{e}}$ & $8.35 \mathrm{E}+04^{\mathrm{e}}$ \\
\hline
\end{tabular}

AF: asymmetry factors; ECF: brain extracellular fluid; $\mathrm{Kp}_{\mathrm{uu}, \mathrm{ECF}}$ : the ratio of the unbound drug concentration in ECF to that in plasma at steady state; PPA: paracellular permeability

${ }^{a}$ Estimated by fitting the observed ECF PK data in control brain to the LeiCNS-PK3.0 model and applied to the LeiCNS-tumor model to obtain the "best basis" for further analyses on tumor compartments

${ }^{\mathrm{b}}$ Calculated from control brain $\mathrm{Kp}_{\mathrm{uu}, \mathrm{ECF}}$ using the LeiCNS-PK3.0 equations at steady state as previously reported (13)

${ }^{\mathrm{c}}$ No correction factor was applied to the control brain model due to the negligible impact on PK profile

${ }^{\mathrm{d}}$ Without PPA correction factor

${ }^{\mathrm{e}}$ Values in patient $\mathrm{C}$

Table VI Fold Changes of Paracellular Pore Size and Active Efflux Clearance in the Brain Tumor BTB Over the Control Brain BBB Estimated by the "Handshake" Approach

\begin{tabular}{|c|c|c|c|c|c|}
\hline \multirow[t]{2}{*}{ Species } & \multirow[t]{2}{*}{ Drug } & \multirow[t]{2}{*}{$\begin{array}{l}\text { PK data } \\
\text { refer- } \\
\text { ence }\end{array}$} & \multirow[t]{2}{*}{ Tumor model } & \multicolumn{2}{|c|}{$\begin{array}{l}\text { Fold changes in the brain tumor } \\
\text { BTB } \\
\text { over the control brain } \mathrm{BBB}^{\mathrm{a}}\end{array}$} \\
\hline & & & & $\begin{array}{l}\text { Paracellular pore } \\
\text { size }\end{array}$ & $\begin{array}{l}\text { Active } \\
\text { efflux } \\
\text { clearance }\end{array}$ \\
\hline \multirow[t]{8}{*}{ Rat brain tumor models } & Methotrexate & (17) & RG-2 & $2.66^{\mathrm{b}}$ & $0.392^{\mathrm{b}}$ \\
\hline & & (18) & R-6 & 17.2 & 0.804 \\
\hline & & $(15)$ & CNS1 & 7.46 & 0.131 \\
\hline & Temozolomide & $(20)$ & SF188/V + & 0.172 & 0.269 \\
\hline & Ganciclovir & $(22)$ & BT4C & 2.50 & 0.101 \\
\hline & Gemcitabine & $(23)$ & C6 & 21.8 & 7.81 \\
\hline & Letrozole & $(24)$ & C6 & 49.1 & $-1.17^{\mathrm{c}}$ \\
\hline & Cisplatin & $(16)$ & $9 \mathrm{~L}$ & 8.12 & 0.0295 \\
\hline Human brain tumor patients & Methotrexate $^{\mathrm{d}}$ & $(25)$ & - & $\begin{array}{l}76.0(\mathrm{~A}) \\
2210(\mathrm{~B})\end{array}$ & $\begin{array}{l}2.62(\mathrm{~A}) \\
54.7(\mathrm{~B})\end{array}$ \\
\hline
\end{tabular}

a Simultaneously estimated by the "handshake" approach, i.e., fitting the observed ECF PK data in brain tumor to the LeiCNS-tumor model integrated with other available pathophysiological parameters shown in Table IV

${ }^{\mathrm{b}}$ Separately estimated with the other parameter fixed to 1

${ }^{c}$ Indicates the involvement of active influx transport as well as the completely diminished active efflux transport

${ }^{\mathrm{d}}$ Parentheses represent patient ID used to predict unbound PK profiles in human patients to support the successful drug development for malignant brain tumors. Nevertheless, it must be of importance to gain a quantitative understanding of the impact of the pathophysiological alterations on unbound PK profiles in experimental animal tumor models, for the right selection of clinical candidates and efficiently translating the understanding to human patients in clinical trials. From 
these points of view, application of PBPK modeling in predicting unbound PK profiles in brain tumor tissues is of great significance not only in human patients but also in animal brain tumor models.

The LeiCNS-PK3.0 model simulations demonstrated that alteration of physiological processes in CNS diseases, especially of paracellular pore size, $\mathrm{pH}$ of ECF and ICF, can affect both rate and extent of passive drug transport across the BBB (14). This result motivated us to extend the LeiCNS-PK3.0 model for the prediction of PK profiles specifically in brain tumors, in combination with information on altered pathophysiological properties in brain tumors. Quantitative information on pathophysiological alterations under disease conditions is the most important requirement in predicting PK profiles in the relevant population.

Physical and biological tumor microenvironment can contribute to the tumor progression, invasion, maintenance of the stem-like fraction and treatment resistance (77-79) as well as the altered drug disposition $(25,80)$. For example, aggressive angiogenesis induced by brain tumors during its progression results in structurally and functionally abnormal blood vessels, leading to alterations of blood flow, volume fraction of MV, and BTB/BBB function compared with healthy brain $(8,81)$. Also, large amounts of protons and lactate produced by aerobic glycolysis in tumor cells are then transported to extracellular space by membrane transporters (70), which creates reversed $\mathrm{pH}$ gradient across cell membrane with more acidic ECF and more basic ICF than healthy brain $(65,66)$. As shown in Fig. 3, blood flow and volume fractions of MV and ECF were higher in CE region of HGG than healthy human brain, LGG, and NE region of HGG, whereas those values in experimental animal brain tumor models were model-dependent, indicating that conditions of their MV differ among models and between preclinical models and clinical settings. These differences may be one of the reasons of discrepancy between drug efficacies in preclinical and clinical, especially in terms of drug delivery to the target tumor tissues. In contrast, lower extracellular $\mathrm{pH}$ and higher intracellular $\mathrm{pH}$ than healthy brain were consistent between animal brain tumor models and human brain tumors. As demonstrated in the previous simulations (14), altered $\mathrm{pH}$ can have a large impact on the rate and extent of the BBB transport of acidic or basic drugs. For example, $\mathrm{Kp}_{\mathrm{uu}, \mathrm{ECF}}$ of methotrexate in RG-2 glioma was equivalent to or slightly lower than that in sham rat brain (Table I, (17)), which may mistakenly lead to the idea that there is no significant alteration of BTB functions in this glioma model compared with the healthy BBB. Methotrexate is acidic and thus is less ionized in more acidic tumor ECF than healthy brain ECF. Therefore, unbound methotrexate concentrations in ECF should be lower in tumor than healthy brain, assuming the same BTB/BBB functions and that only unionized molecule can pass through the BTB/BBB via transcellular pathway. In our model analysis including $\mathrm{pH}$ information, altered BTB function in RG-2 glioma model was actually estimated (2.66-fold increase of paracellular pore size or 2.55-fold decrease of active efflux CL over control (sham) brain BBB, Table VI) even though $\mathrm{Kp}_{\mathrm{uu}, \mathrm{ECF}}$ are almost the same. This result is a good example showing the significance of considering $\mathrm{pH}$ differences in interpreting and analyzing PK data in multiple tissues or under different (patho-) physiological conditions.

We unexpectedly found that reduction of PPA improved the description of PK profiles of some drugs in control brain ECF (Table IV, Supplementary Fig.S1 and Fig. 2). It should be noted again that the LeiCNS-PK3.0 model prediction of control brain ECF PK profiles without PPA correction was acceptable (within twofold error for most data points, see Supplementary Fig.S1) as our previous study (13) and no PPA correction was required for letrozole and cisplatin. Accordingly, we believe the utility of the LeiCNS-PK3.0 model as the healthy brain model has not been changed by the findings in this study. Considering that all drugs in this study but letrozole are highly hydrophilic $\left(\log \mathrm{P}_{\mathrm{o} / \mathrm{w}}<0\right)$ whereas only limited number of hydrophilic drugs were included in the original study (13), however, these findings indicate that the LeiCNS-PK3.0 model may overestimate passive transport rate across the BBB of highly hydrophilic drugs whose major transport route is estimated to be the paracellular pathway. It is worth noting that most drug candidates targeting CNS are generally not highly hydrophilic. Nevertheless, we consider these findings indicating an improvement opportunity of the LeiCNS-PK3.0 model. Possible explanations of PPA overestimation by the LeiCNSPK3.0 model in this study include charge effect, size effect, tortuosity, and study conditions. Firstly, PPA of negatively charged molecules across Caco-2 monolayer and several BMEC models was reported to be about half of uncharged molecule with similar molecular size, due to the negatively charged residues lining the paracellular pores $(82,83)$. Secondly, at least a part of paracellular pores are size-restricted, where PPA can be described by the Renkin hydrodynamic sieving function $(83,84)$. These effects are probably the main reasons why estimated PPA correction factors were higher for methotrexate than those for other drugs except for gemcitabine. Thirdly, tortuosity of paracellular pathway needs to be considered (82). These three factors are currently not specified in the LeiCNS-PK3.0 model and should be addressed in future research. In addition, it is also possible that study conditions including animal strain, experimental apparatus, and MD probe location, make inter-laboratory differences in the BBB condition. The LeiCNS-PK3.0 model has an advantage in capturing many details of general CNS physiology at the species level, but physiology may be different within species (i.e., between rat strains). We expect that expanding the validation dataset will allow to include 
above factors and further improve the estimation of PPA based on the physicochemical properties.

Alterations of paracellular pore size (35-37) and expression levels of active efflux transporters $(38,85)$ in the BTB in animal glioma models or human GBM patients from the healthy brain BBB are reported. However, quantitative information on these two parameters are currently very limited compared with other pathophysiological parameters, even though they are essential for the PK prediction with the LeiCNS-tumor model. Instead, we estimated both parameters by fitting existing PK data in tumor ECF to our model integrated with other available pathophysiological parameters. We believe this is the best possible approach to address the lack of quantitative information and quite useful to learn about what could happen in disease conditions for which so little quantitative data is available. First, the increase of paracellular pore size of the tumor BTB compared with the control brain BBB was estimated in 8 out of 9 cases including human patients (Table VI), which is consistent with general belief of leakier MV in brain tumors $(5,6)$. The only exception was temozolomide in the SF188/V + glioma model rats. Since temozolomide is highly hydrophilic $\left(\log \mathrm{P}_{\mathrm{o} / \mathrm{w}}=-1.153\right)$, paracellular route is estimated to account for $>99.6 \%$ of its passive transport across the BBB by the LeiCNS-PK3.0 model. Therefore, the increase of paracellular pore size of the BTB should lead to the increase of PPA across the BTB and tumor ECF exposure, whereas existing data show its ECF exposure in tumor is slightly lower than in contralateral brain (Table I, (20)). Considering many reports describing temozolomide as a lipophilic drug (86-88), it may be able to efficiently permeate a lipid bilayer somehow, despite its extremely low $\log \mathrm{P}_{\mathrm{o} / \mathrm{w}}$. Indeed, Dr. Avdeef estimated that transcellular route is the major passive transport pathway of temozolomide (89). This is also a significant subject for future studies to improve the prediction of transport rate across the BBB. The range of fold change of BTB paracellular pore size was between 0.172 and 2210, which indicates model- and condition-dependent alteration of the BTB integrity in brain tumors. The fold change of 2210 (paracellular pore size of $1547 \mathrm{~nm}$ ) for methotrexate in patient B was exceptionally high, nevertheless, it is comparable to the mean BTB paracellular pore size in RG-2 glioma model rats, $1.1 \mu \mathrm{m}$ (36). Other cases are consistent with the reported range of upper limit of BTB paracellular pore size, 7-100 nm (37). In addition, the current analysis suggests that opening of paracellular pore of the BTB in brain tumors is common between animal models and human patients, while only one human case (two patients) was available in this study. We expect expanding data set will allow to examine the possibility of quantitative extrapolation directly from animal models to human patients regarding the paracellular pore size of the BTB in brain tumors.

Next, the decrease of active efflux CL at the BTB compared with the control brain BBB was estimated in 7 out of
9 cases (Table VI), which is consistent with recent publication reporting significant reduction of $\mathrm{ABCB} 1$ and $\mathrm{ABCG} 2$ protein abundances in isolated $\mathrm{MV}$ of GBM in human patients compared with non-cancerous cerebral cortex (38). Although no quantitative information is available for other transporters and animal brain tumor models, similar pathophysiological alterations would be highly possible. Importantly, protein abundances of all efflux transporters measured (ABCB1, ABCG2, and ABCC4) in MV of GBM were below the lower limit of quantification in some patients (38), which is consistent with the disappeared active efflux transport of letrozole estimated in the current analysis. Two exceptional cases are gemcitabine in the $\mathrm{C} 6$ glioma model rats and methotrexate in human HGG patients. Efflux transporters for gemcitabine include P-gp, MRP1, MRP5, and MRP7 (Supplementary Table S2). Considering that active efflux transport of letrozole, a weak P-gp substrate (90), was estimated to be completely diminished at the BTB in the same C6 glioma model, upregulation of MRPs might explain this exceptional case. However, it is difficult to precisely interpret this result with limited information. In human patients, MRP5 protein was abundantly detected in the BMEC of almost all glioma samples, whereas MRP1 was not detected on the protein level (91). Methotrexate is recognized by quite various transporters (Supplementary Table S2), but a series of transporter knockout mice studies (92-96) indicates that BCRP and MRP4 mainly contribute to the active efflux of methotrexate at the BBB at least in mice. Considering that median BCRP protein level in MV of GBM was reduced to $35 \%$ of normal levels whereas MRP4 was undetectable in both normal human brain and GBM (38), the present estimate of higher active efflux CL at the BTB in HGG than that at the control brain BBB seems inappropriate. This discrepancy may be explained by the level of active efflux transport function at the BBB in control brain used as the "best basis" in this analysis. We selected PK data in NE brain region of patient $\mathrm{C}$ as the "best basis" for an appropriate understanding of the impact of pathophysiological alterations in HGG because the model analysis indicated that active efflux transport was completely disappeared in NE region of patient D (Supplementary Table S1). However, it is highly possible that active efflux transport function was already decreased also in patient $\mathrm{C}$. In fact, extrapolation of human active efflux CL from rat data based on the relative expression factor approach $(97,98)$ largely underestimated the ECF exposure of methotrexate in patient C (data not shown). Furthermore, similar finding has recently been reported by Li et al. (99), where reduction of ABCB1 abundance compared with the non-cancerous brain $\mathrm{BBB}$ was required to describe unbound $\mathrm{PK}$ profile of ribociclib in $\mathrm{NE}$ brain region of GBM patients. Although a lack of accumulation of contrast agents in NE brain regions indicates an intact BBB function in terms of limited PPA by tight junctions, 
micrometastatic tumor cells may possibly exist there $(3,8$, 9) and affect the efflux transporter functions, possibly more drastically than in $\mathrm{CE}$ region.

The LeiCNS-tumor model predicted tumor ECF PK profiles within twofold error for most data points (Fig. 2), in combination with estimated fold changes of paracellular pore size of the BTB and active efflux CL at the BTB over the control brain BBB. Although further validation with more drugs is required, this result suggest that the LeiCNS-tumor model can be used to predict tumor ECF PK for which pathophysiological parameters are available. Importantly, five pathophysiological parameters (blood flow, volume fractions of MV and ECF, and extracellular/intracellular $\mathrm{pH}$ ) in brain tumors are available from literature for various brain tumor models and tumor types (Fig. 3). Accordingly, it is possible to predict tumor ECF PK depending on the tumor models, tumor types and tumor grades. The lack of two pathophysiological parameters disables the fully "bottom-up" model building and instead we estimated them by fitting existing data in this study. These estimates represent the BTB function of each animal tumor model and human patient analyzed in this study, i.e., model- and patient-specific parameters. Considering the different estimates in the same $\mathrm{C} 6$ glioma model rats for gemcitabine and letrozole, careful consideration of small changes of experimental conditions (e.g., days after inoculation of tumor cells) is required. Nevertheless, once the model-specific estimates of these two parameters are obtained for each animal brain tumor model, the LeiCNS-tumor model can be used to predict tumor ECF PK profiles of other drugs in the same animal model using the model-specific estimates, available pathophysiological parameters, $\mathrm{Kp}_{\mathrm{uu}, \mathrm{ECF}}$ in healthy brain and physicochemical properties of drugs of interest. Accordingly, we believe our model has a potential to improve the efficiency of drug discovery process for malignant brain tumors, through enhancing the efficient understanding of PKPD relationships of brain tumors as well as the right selection of drug candidates for clinical trials.

All drugs but temozolomide in this study showed higher ECF exposure in brain tumor than in control brain. Other molecules including contrast agents $(7,9)$, ribociclib (99), paclitaxel (100, 101), and Texas Red (101) also demonstrated higher exposure in brain tumors. Although these results are consistent with the generally believed leakier MV in brain tumors $(5,6)$, they are inconsistent with the poor success rate of clinical candidates for malignant brain tumors and may be unintuitive. As stated above, micrometastatic tumor cells protected by the intact BBB can cause tumor recurrence, which is one of the significant reasons of difficulty in treating malignant brain tumors. In addition, it is important to note that higher exposure in brain tumor tissue does not necessarily expect desired anti-tumor efficacy and therefore an appropriate understanding of PKPD relationship is necessary for the successful drug development for malignant brain tumors.

There are several limitations in our new LeiCNS-tumor model. First, some parameters in tumor compartments were assumed to be the same as healthy brain due to the lack of quantitative information available. In particular, ECF bulk flow may be different between brain tumor and healthy brain, considering that tumor has an increased interstitial fluid pressure and the dense extracellular matrix $(77,81$, 102). Recent progress of magnetic resonance imaging (MRI) technique is expected to enable the measurement of tumor ECF bulk flow (103). Second, only a limited number of drugs are evaluated in the present study. More drugs, with distinctively different physicochemical properties, are needed to be included in the future analyses. Third, no spatial information is considered in the present model. Concentrations of drugs which penetrate the disrupted BTB more efficiently than the intact BBB are likely to be highest in the tumor core and decrease with distance from the core, in the order of tumor periphery, tumor edge-brain interface, BAT, and healthy brain distant from tumor $(100,101)$. Dividing the tumor model into several regional tumor models including heterogenous MV properties will be quite informative and a relevant subject for future research. Moreover, a 3D modeling approach (104-106) in combination with spatial information on pathophysiology is expected to allow the prediction of local distribution of drugs and biomarkers. Finally, PBPK model analyses depend on the availability of quantitative information on (patho-) physiology. As far as we know, there is no quantitative information on paracellular pore size of the BTB and only limited information on expression levels of active transporters at the BTB in brain tumor patients. In order to effectively utilize the LeiCNS-tumor model for improving the possibility of success in drug development for malignant brain tumors through predicting PK profiles in brain tumors, more quantitative information on tumor pathophysiological alterations, especially paracellular pore size of the BTB and expression levels of active transporters at the BTB, is desired. Although estimation of these parameters based on MD data in human patients may be difficult as demonstrated in this study for methotrexate, fitting MRI data with contrast agents to our model will allow to estimate heterogenous paracellular pore size of the BTB in human patients. Furthermore, considering that MRI with contrast agents is a standard diagnosis of brain tumors (7), this approach will be able to give not only representative parameters (e.g., mean) in the relevant population but also individual parameters which may allow the "tailor-made" PK prediction in each patient. In addition, quantitative information on the expression levels of active transporters in tumor MV by LC-MS/MS-based targeted proteomics $(38,39)$, instead of parameter estimation by fitting, will further enhance the predictability and utility of the LeiCNS-tumor model. 


\section{Conclusion}

In conclusion, we extended the LeiCNS-PK3.0 model specifically for the prediction of brain tumor ECF PK profiles by adding brain tumor compartments and integrating pathophysiological parameters of brain tumors. The LeiCNS-tumor model was able to describe the ECF PK profiles in brain tumor as well as control brain in combination with estimated paracellular pore size of the BTB and active efflux CL at the brain tumor BTB. Although further research is required, the current results demonstrated its potential to contribute to the efficient drug discovery and development for malignant brain tumors.

Supplementary Information The online version contains supplementary material available at https://doi.org/10.1007/s11095-021-03154-1.

ACKNOWLEDGMENTS AND DISCLOSURES Makoto Hirasawa is an employee of Daiichi-Sankyo Co., Ltd.

Author Contributions Makoto Hirasawa and Elizabeth C.M de Lange contributed to the project design and model improvement. Mohammed A.A Saleh provided technical support on running the LeiCNS-PK3.0 model. Makoto Hirasawa performed data collection and model simulations. Makoto Hirasawa, Mohammed A.A Saleh and Elizabeth C.M de Lange contributed to manuscript writing.

Funding This study was supported by Daiichi-Sankyo Co., Ltd.

Data Availability Data generated during and analyzed during the current study are not publicly available due privacy but are available from the corresponding author on reasonable request.

Open Access This article is licensed under a Creative Commons Attribution 4.0 International License, which permits use, sharing, adaptation, distribution and reproduction in any medium or format, as long as you give appropriate credit to the original author(s) and the source, provide a link to the Creative Commons licence, and indicate if changes were made. The images or other third party material in this article are included in the article's Creative Commons licence, unless indicated otherwise in a credit line to the material. If material is not included in the article's Creative Commons licence and your intended use is not permitted by statutory regulation or exceeds the permitted use, you will need to obtain permission directly from the copyright holder. To view a copy of this licence, visit http://creativecommons.org/licenses/by/4.0/.

\section{References}

1. Ostrom QT, Patil N, Cioffi G, Waite K, Kruchko C, BarnholtzSloan JS. CBTRUS statistical report: primary brain and other central nervous system tumors diagnosed in the United States in 2013-2017. Neuro Oncol. 2020;22(12 Suppl 2):iv1-96. https:// doi.org/10.1093/neuonc/noaa200.

2. Fisher JP, Adamson DC. Current FDA-approved therapies for high-grade malignant gliomas. Biomedicines. 2021;9(3):324. https://doi.org/10.3390/biomedicines9030324.

3. Sarkaria JN, Hu LS, Parney IF, Pafundi DH, Brinkmann DH, Laack NN, et al. Is the blood-brain barrier really disrupted in all glioblastomas? A critical assessment of existing clinical data. Neuro Oncol. 2018;20(2):184-91. https://doi.org/10.1093/neuonc/nox 175 .

4. de Lange EC. The physiological characteristics and transcytosis mechanisms of the blood-brain barrier (BBB). Curr Pharm Biotechnol. 2012;13(12):2319-27. https://doi.org/10.2174/13892 0112803341860 .

5. Hempel C, Johnsen KB, Kostrikov S, Hamerlik P, Andresen TL. Brain tumor vessels-a barrier for drug delivery. Cancer Metastasis Rev. 2020;39(3):959-68. https://doi.org/10.1007/ s10555-020-09877-8.

6. van Tellingen $\mathrm{O}$, Yetkin-Arik B, de Gooijer MC, Wesseling P, Wurdinger T, de Vries HE. Overcoming the blood-brain tumor barrier for effective glioblastoma treatment. Drug Resist Updat. 2015;19:1-12. https://doi.org/10.1016/j.drup.2015.02.002.

7. Cao Y, Sundgren PC, Tsien CI, Chenevert TT, Junck L. Physiologic and metabolic magnetic resonance imaging in gliomas. J Clin Oncol. 2006;24(8):1228-35. https://doi.org/10.1200/JCO. 2005.04.7233.

8. Arvanitis CD, Ferraro GB, Jain RK. The blood-brain barrier and blood-tumour barrier in brain tumours and metastases. Nat Rev Cancer. 2020;20(1):26-41. https://doi.org/10.1038/ s41568-019-0205-x.

9. Eidel O, Burth S, Neumann JO, Kieslich PJ, Sahm F, Jungk C, et al. Tumor Infiltration in enhancing and non-enhancing parts of glioblastoma: a correlation with histopathology. PLoS ONE. 2017;12(1):e0169292. https://doi.org/10.1371/journal.pone. 0169292.

10. Pokorny JL, Calligaris D, Gupta SK, Iyekegbe DO Jr, Mueller D, Bakken KK, et al. The efficacy of the Wee1 inhibitor MK-1775 Combined with temozolomide is limited by heterogeneous distribution across the blood-brain barrier in glioblastoma. Clin Cancer Res. 2015;21(8):1916-24. https://doi.org/10.1158/10780432.CCR-14-2588.

11. Lockman PR, Mittapalli RK, Taskar KS, Rudraraju V, Gril B, Bohn KA, et al. Heterogeneous blood-tumor barrier permeability determines drug efficacy in experimental brain metastases of breast cancer. Clin Cancer Res. 2010;16(23):5664-78. https:// doi.org/10.1158/1078-0432.CCR-10-1564.

12. Gril B, Wei D, Zimmer AS, Robinson C, Khan I, Difilippantonio $\mathrm{S}$, et al. HER2 antibody-drug conjugate controls growth of breast cancer brain metastases in hematogenous xenograft models, with heterogeneous blood-tumor barrier penetration unlinked to a passive marker. Neuro Oncol. 2020;22(11):1625-36. https://doi.org/ 10.1093/neuonc/noaa118.

13. Saleh MAA, Loo CF, Elassaiss-Schaap J, De Lange ECM. Lumbar cerebrospinal fluid-to-brain extracellular fluid surrogacy is context-specific: insights from LeiCNS-PK3.0 simulations. J Pharmacokinet Pharmacodyn. 2021;48(5):725-41. https://doi. org/10.1007/s10928-021-09768-7.

14. Saleh MAA, de Lange ECM. Impact of CNS diseases on drug delivery to brain extracellular and intracellular target sites in human: a "WHAT-IF" simulation study. Pharmaceutics. 2021;13(1):95. https://doi.org/10.3390/pharmaceutics13 010095.

15. Dukic SF, Kaltenbach ML, Heurtaux T, Hoizey G, Lallemand A, Vistelle R. Influence of C6 and CNS1 brain tumors on methotrexate pharmacokinetics in plasma and brain tissue. $\mathbf{J}$ Neurooncol. 2004;67(1-2):131-8. https://doi.org/10.1023/b: neon.0000021820.12444.4c.

16. Nakashima M, Shibata S, Tokunaga Y, Fujita H, Anda T, Arizono $\mathrm{K}$, et al. In-vivo microdialysis study of the distribution of cisplatin into brain tumour tissue after intracarotid infusion in rats with 9L malignant glioma. J Pharm Pharmacol. 1997;49(8):777-80. https://doi.org/10.1111/j.2042-7158.1997. tb06111.x. 
17. Devineni D, Klein-Szanto A, Gallo JM. In vivo microdialysis to characterize drug transport in brain tumors: analysis of methotrexate uptake in rat glioma-2 (RG-2)-bearing rats. Cancer Chemother Pharmacol. 1996;38(6):499-507. https://doi. org/10.1007/s002800050518.

18. de Lange EC, de Vries JD, Zurcher C, Danhof M, de Boer AG, Breimer DD. The use of intracerebral microdialysis for the determination of pharmacokinetic profiles of anticancer drugs in tumor-bearing rat brain. Pharm Res. 1995;12(12):1924-31. https://doi.org/10.1023/a:1016239822287.

19. Westerhout J, van den Berg DJ, Hartman R, Danhof M, de Lange EC. Prediction of methotrexate CNS distribution in different species - influence of disease conditions. Eur J Pharm Sci. 2014;57:11-24. https://doi.org/10.1016/j.ejps.2013.12. 020.

20. Zhou Q, Guo P, Kruh GD, Vicini P, Wang X, Gallo JM. Predicting human tumor drug concentrations from a preclinical pharmacokinetic model of temozolomide brain disposition. Clin Cancer Res. 2007;13(14):4271-9. https://doi.org/10.1158/ 1078-0432.CCR-07-0658.

21. Arora P, Adams CH, Gudelsky G, DasGupta B, Desai PB. Plasma and brain pharmacokinetics of letrozole and drug interaction studies with temozolomide in NOD-scid gamma mice and sprague dawley rats. Cancer Chemother Pharmacol. 2019;83(1):81-9. https://doi.org/10.1007/s00280-018-3705-6.

22. Gynther M, Kääriäinen TM, Hakkarainen JJ, Jalkanen AJ, Petsalo A, Lehtonen M, et al. Brain pharmacokinetics of ganciclovir in rats with orthotopic BT4C glioma. Drug Metab Dispos. 2015;43(1):140-6. https://doi.org/10.1124/dmd.114.059840.

23. Apparaju SK, Gudelsky GA, Desai PB. Pharmacokinetics of gemcitabine in tumor and non-tumor extracellular fluid of brain: an in vivo assessment in rats employing intracerebral microdialysis. Cancer Chemother Pharmacol. 2008;61(2):2239. https://doi.org/10.1007/s00280-007-0464-1.

24. Dave N, Gudelsky GA, Desai PB. The pharmacokinetics of letrozole in brain and brain tumor in rats with orthotopically implanted C6 glioma, assessed using intracerebral microdialysis. Cancer Chemother Pharmacol. 2013;72(2):349-57. https:// doi.org/10.1007/s00280-013-2205-y.

25. Blakeley JO, Olson J, Grossman SA, He X, Weingart J, Supko JG, et al. Effect of blood brain barrier permeability in recurrent high grade gliomas on the intratumoral pharmacokinetics of methotrexate: a microdialysis study. J Neurooncol. 2009;91(1):51-8. https://doi.org/10.1007/s11060-008-9678-2.

26. Skibińska L, Ramlau C, Załuski J, Olejniczak B. Methotrexate binding to human plasma proteins. Pol J Pharmacol Pharm. 1990;42(2):151-7.

27. Yamamoto Y, Välitalo PA, Huntjens DR, Proost JH, Vermeulen A, Krauwinkel W, et al. Predicting drug concentration-time profiles in multiple CNS compartments using a comprehensive physiologically-based pharmacokinetic model. CPT Pharmacometrics Syst Pharmacol. 2017;6(11):765-77. https://doi.org/ 10.1002/psp4.12250.

28. Bauer RJ. NONMEM Users guide: Introduction to NONMEM 7.4.3. 2019; In: ICON Plc

29. Team RC. R: A language and environment for statistical computing. 2019; R Foundation for Statistical Computing, Vienna, Austria.

30. Fidler M, Hallow M, Wilkins J, Wang W. RxODE: Facilities for Simulating from ODE-Based Models; 2019

31. Wishart DS, Feunang YD, Guo AC, Lo EJ, Marcu A, Grant JR, et al. DrugBank 5.0: a major update to the DrugBank database for 2018. Nucleic Acids Res. 2018;46(D1):D1074-82. https:// doi.org/10.1093/nar/gkx1037.
32. Manchester J, Walkup G, Rivin O, You Z. Evaluation of pKa estimation methods on 211 druglike compounds. J Chem Inf Model. 2010;50(4):565-71. https://doi.org/10.1021/ci100019p.

33. Roberts TA, Hyare H, Agliardi G, Hipwell B, d'Esposito A, Ianus A, et al. Noninvasive diffusion magnetic resonance imaging of brain tumour cell size for the early detection of therapeutic response. Sci Rep. 2020;10(1):9223. https://doi.org/10. 1038/s41598-020-65956-4.

34. Reynaud O, Winters KV, Hoang DM, Wadghiri YZ, Novikov DS, Kim SG. Pulsed and oscillating gradient MRI for assessment of cell size and extracellular space (POMACE) in mouse gliomas. NMR Biomed. 2016;29(10):1350-63. https://doi.org/ 10.1002/nbm.3577.

35. Sarin H, Kanevsky AS, Wu H, Brimacombe KR, Fung SH, Sousa AA, et al. Effective transvascular delivery of nanoparticles across the blood-brain tumor barrier into malignant glioma cells. J Transl Med. 2008;6:80. https://doi.org/10.1186/ 1479-5876-6-80.

36. Schlageter KE, Molnar P, Lapin GD, Groothuis DR. Microvessel organization and structure in experimental brain tumors: microvessel populations with distinctive structural and functional properties. Microvasc Res. 1999;58(3):312-28. https:// doi.org/10.1006/mvre.1999.2188.

37. Hobbs SK, Monsky WL, Yuan F, Roberts WG, Griffith L, Torchilin VP, et al. Regulation of transport pathways in tumor vessels: role of tumor type and microenvironment. Proc Natl Acad Sci U S A. 1998;95(8):4607-12. https://doi.org/10.1073/ pnas.95.8.4607.

38. Bao X, Wu J, Xie Y, Kim S, Michelhaugh S, Jiang J, et al. Protein expression and functional relevance of efflux and uptake drug transporters at the blood-brain barrier of human brain and glioblastoma. Clin Pharmacol Ther. 2020;107(5):1116-27. https://doi.org/10.1002/cpt.1710.

39. Bao X, Wu J, Jiang J, Tien AC, Sanai N, Li J. Quantitative protein expression of blood-brain barrier transporters in the vasculature of brain metastases of patients with lung and breast cancer. Clin Transl Sci. 2021;14(4):1265-71. https://doi.org/ $10.1111 /$ cts. 12978 .

40. Nomura T, Ikezaki K, Natori Y, Fukui M. Altered response to histamine in brain tumor vessels: the selective increase of regional cerebral blood flow in transplanted rat brain tumor. J Neurosurg. 1993;79(5):722-8. https://doi.org/10.3171/jns. 1993.79.5.0722.

41. Johansson M, Bergenheim AT, Henriksson R, Koskinen LO, Vallbo C, Widmark A. Tumor blood flow and the cytotoxic effects of estramustine and its constituents in a rat glioma model. Neurosurgery. 1997;41(1):237-43. https://doi.org/10. 1097/00006123-199707000-00038 (discussion 243-4).

42. Groothuis DR, Fischer JM, Pasternak JF, Blasberg RG, Vick NA, Bigner DD. Regional measurements of blood-to-tissue transport in experimental RG-2 rat gliomas. Cancer Res. 1983;43(7):3368-73.

43. Jerome NP, Hekmatyar SK, Kauppinen RA. Blood oxygenation level dependent, blood volume, and blood flow responses to carbogen and hypoxic hypoxia in 9L rat gliomas as measured by MRI. J Magn Reson Imaging. 2014;39(1):110-9. https://doi.org/ 10.1002/jmri.24097.

44. Sun Y, Schmidt NO, Schmidt K, Doshi S, Rubin JB, Mulkern $\mathrm{RV}$, et al. Perfusion MRI of U87 brain tumors in a mouse model. Magn Reson Med. 2004;51(5):893-9. https://doi.org/10.1002/ mrm.20029.

45. Zhou J, Tryggestad E, Wen Z, Lal B, Zhou T, Grossman R, et al. Differentiation between glioma and radiation necrosis using molecular magnetic resonance imaging of endogenous proteins 
and peptides. Nat Med. 2011;17(1):130-4. https://doi.org/10. 1038/nm.2268.

46. Grossman R, Tyler B, Brem H, Eberhart CG, Wang S, Fu DX, et al. Growth properties of SF188/V+ human glioma in rats in vivo observed by magnetic resonance imaging. $\mathrm{J}$ Neurooncol. 2012;110(3):315-23. https://doi.org/10.1007/ s11060-012-0974-5.

47. Hakyemez B, Erdogan C, Ercan I, Ergin N, Uysal S, Atahan S. High-grade and low-grade gliomas: differentiation by using perfusion MR imaging. Clin Radiol. 2005;60(4):493-502. https:// doi.org/10.1016/j.crad.2004.09.009.

48. Puig J, Blasco G, Daunis-I-Estadella J, Alberich-Bayarri A, Essig M, Jain R, et al. High-resolution blood-pool-contrast-enhanced MR angiography in glioblastoma: tumor-associated neovascularization as a biomarker for patient survival. A preliminary study. Neuroradiology. 2016;58(1):17-26. https://doi.org/10.1007/ s00234-015-1599-0.

49. Wolf RL, Wang J, Wang S, Melhem ER, O'Rourke DM, Judy $\mathrm{KD}$, et al. Grading of CNS neoplasms using continuous arterial spin labeled perfusion MR imaging at 3 Tesla. J Magn Reson Imaging. 2005;22(4):475-82. https://doi.org/10.1002/jmri. 20415.

50. Yoo RE, Choi SH, Cho HR, Kim TM, Lee SH, Park CK, et al. Tumor blood flow from arterial spin labeling perfusion MRI: a key parameter in distinguishing high-grade gliomas from primary cerebral lymphomas, and in predicting genetic biomarkers in high-grade gliomas. J Magn Reson Imaging. 2013;38(4):852-60. https://doi.org/10.1002/jmri.24026.

51. Cha S, Johnson G, Wadghiri YZ, Jin O, Babb J, Zagzag D, et al. Dynamic, contrast-enhanced perfusion MRI in mouse gliomas: correlation with histopathology. Magn Reson Med. 2003;49(5):848-55. https://doi.org/10.1002/mrm.10446.

52. Valable S, Lemasson B, Farion R, Beaumont M, Segebarth C, Remy C, et al. Assessment of blood volume, vessel size, and the expression of angiogenic factors in two rat glioma models: a longitudinal in vivo and ex vivo study. NMR Biomed. 2008;21(10):1043-56. https://doi.org/10.1002/nbm.1278.

53. Julien C, Payen JF, Troprès I, Farion R, Grillon E, Montigon $\mathrm{O}$, et al. Assessment of vascular reactivity in rat brain glioma by measuring regional blood volume during graded hypoxic hypoxia. Br J Cancer. 2004;91(2):374-80. https://doi.org/10. 1038/sj.bjc.6601908.

54. Huszthy PC, Brekken C, Pedersen TB, Thorsen F, Sakariassen PO, Skaftnesmo KO, et al. Antitumor efficacy improved by local delivery of species-specific endostatin. J Neurosurg. 2006;104(1):118-28. https://doi.org/10.3171/jns.2006.104.1.118.

55. Li X, Rooney WD, Várallyay CG, Gahramanov S, Muldoon LL, Goodman JA, et al. Dynamic-contrast-enhanced-MRI with extravasating contrast reagent: rat cerebral glioma blood volume determination. J Magn Reson. 2010;206(2):190-9. https://doi. org/10.1016/j.jmr.2010.07.004.

56. Chakhoyan A, Corroyer-Dulmont A, Leblond MM, Gérault A, Toutain J, Chazaviel L, et al. Carbogen-induced increases in tumor oxygenation depend on the vascular status of the tumor: A multiparametric MRI study in two rat glioblastoma models. J Cereb Blood Flow Metab. 2017;37(6):2270-82. https://doi.org/ 10.1177/0271678X16663947.

57. Abe T, Mizobuchi Y, Nakajima K, Otomi Y, Irahara S, Obama Y, et al. Diagnosis of brain tumors using dynamic contrast-enhanced perfusion imaging with a short acquisition time. Springerplus. 2015;4:88. https://doi.org/10.1186/s40064-015-0861-6.

58. Law M, Yang S, Babb JS, Knopp EA, Golfinos JG, Zagzag D, et al. Comparison of cerebral blood volume and vascular permeability from dynamic susceptibility contrast-enhanced perfusion
MR imaging with glioma grade. AJNR Am J Neuroradiol. 2004;25(5):746-55.

59. John F, Robinette NL, Amit-Yousif AJ, Bosnyák E, Barger GR, Shah KD, et al. Multimodal imaging of nonenhancing glioblastoma regions. Mol Imaging. 2019;18:1536012119885222. https://doi.org/10.1177/1536012119885222.

60. Chwang WB, Jain R, Bagher-Ebadian H, Nejad-Davarani SP, Iskander AS, VanSlooten A, et al. Measurement of rat brain tumor kinetics using an intravascular MR contrast agent and DCE-MRI nested model selection. J Magn Reson Imaging. 2014;40(5):1223-9. https://doi.org/10.1002/jmri.24469.

61. Rygh CB, Wang J, Thuen M, Gras Navarro A, Huuse EM, Thorsen F, et al. Dynamic contrast enhanced MRI detects early response to adoptive NK cellular immunotherapy targeting the NG2 proteoglycan in a rat model of glioblastoma. PLoS ONE. 2014;9(9):e108414. https://doi.org/10.1371/journal.pone.0108414.

62. Brown SL, Nagaraja TN, Aryal MP, Panda S, Cabral G, Keenan $\mathrm{KA}$, et al. MRI-tracked tumor vascular changes in the hours after single-fraction irradiation. Radiat Res. 2015;183(6):713-21. https://doi.org/10.1667/RR13458.1.

63. Bruehlmeier M, Roelcke U, Bläuenstein P, Missimer J, Schubiger PA, Locher JT, et al. Measurement of the extracellular space in brain tumors using 76Br-bromide and PET. J Nucl Med. 2003;44(8):1210-8.

64. Zamecnik J. The extracellular space and matrix of gliomas. Acta Neuropathol. 2005;110(5):435-42. https://doi.org/10.1007/ s00401-005-1078-5.

65. Lim H, Albatany M, Martínez-Santiesteban F, Bartha R, Scholl TJ. Longitudinal Measurements of Intra- and Extracellular $\mathrm{pH}$ Gradient in a Rat Model of Glioma. Tomography. 2018;4(2):4654. https://doi.org/10.18383/j.tom.2018.00001.

66. Hao G, Xu ZP, Li L. Manipulating extracellular tumour pH: An effective target for cancer therapy. RSC Adv. 2018;8(39):2218292. https://doi.org/10.1039/c8ra02095g.

67. Coman D, Huang Y, Rao JU, De Feyter HM, Rothman DL, Juchem C, et al. Imaging the intratumoral-peritumoral extracellular pH gradient of gliomas. NMR Biomed. 2016;29(3):309-19. https://doi.org/10.1002/nbm.3466.

68. Ferrauto G, Di Gregorio E, Auboiroux V, Petit M, Berger F, Aime S, et al. CEST-MRI for glioma $\mathrm{pH}$ quantification in mouse model: Validation by immunohistochemistry. NMR Biomed. 2018;31(11):e4005. https://doi.org/10.1002/nbm.4005.

69. Rao JU, Coman D, Walsh JJ, Ali MM, Huang Y, Hyder F. Temozolomide arrests glioma growth and normalizes intratumoral extracellular pH. Sci Rep. 2017;7(1):7865. https://doi. org/10.1038/s41598-017-07609-7.

70. Swietach P, Vaughan-Jones RD, Harris AL, Hulikova A. The chemistry, physiology and pathology of $\mathrm{pH}$ in cancer. Philos Trans R Soc Lond B Biol Sci. 2014;369(1638):20130099. https://doi.org/10.1098/rstb.2013.0099.

71. Beaumont M, Lemasson B, Farion R, Segebarth C, Rémy C, Barbier EL. Characterization of tumor angiogenesis in rat brain using iron-based vessel size index MRI in combination with gadolinium-based dynamic contrast-enhanced MRI. J Cereb Blood Flow Metab. 2009;29(10):1714-26. https://doi.org/10. 1038/jcbfm.2009.86.

72. Ma J, Pulfer S, Li S, Chu J, Reed K, Gallo JM. Pharmacodynamic-mediated reduction of temozolomide tumor concentrations by the angiogenesis inhibitor TNP-470. Cancer Res. 2001;61(14):5491-8.

73. Dréan A, Goldwirt L, Verreault M, Canney M, Schmitt C, Guehennec J, et al. Blood-brain barrier, cytotoxic chemotherapies and glioblastoma. Expert Rev Neurother. 2016;16(11):1285-300. https://doi.org/10.1080/14737175.2016.1202761. 
74. Yamamoto Y, Danhof M, de Lange ECM. Microdialysis: the key to physiologically based model prediction of human CNS target site concentrations. AAPS J. 2017;19(4):891-909. https://doi. org/10.1208/s12248-017-0050-3.

75. Pierce CF, Kwasnicki A, Lakka SS, Engelhard HH. Cerebral microdialysis as a tool for assessing the delivery of chemotherapy in brain tumor patients. World Neurosurg. 2021;145:187-96. https://doi.org/10.1016/j.wneu.2020.08.161.

76. Liu L, Zhang X, Lou Y, Rao Y, Zhang X. Cerebral microdialysis in glioma studies, from theory to application. J Pharm Biomed Anal. 2014;96:77-89. https://doi.org/10.1016/j.jpba.2014.03. 026.

77. Stylianopoulos T, Munn LL, Jain RK. Reengineering the physical microenvironment of tumors to improve drug delivery and efficacy: from mathematical modeling to bench to bedside. Trends Cancer. 2018;4(4):292-319. https://doi.org/10.1016/j.trecan. 2018.02.005.

78. Manini I, Caponnetto F, Bartolini A, Ius T, Mariuzzi L, Di Loreto $\mathrm{C}$, et al. Role of microenvironment in glioma invasion: what we learned from in vitro models. Int J Mol Sci. 2018;19(1):147. https://doi.org/10.3390/ijms19010147.

79. Hardee ME, Zagzag D. Mechanisms of glioma-associated neovascularization. Am J Pathol. 2012;181(4):1126-41. https://doi. org/10.1016/j.ajpath.2012.06.030.

80. Bergenheim AT, Roslin M, Ungerstedt U, Waldenström A, Henriksson R, Ronquist G. Metabolic manipulation of glioblastoma in vivo by retrograde microdialysis of $\mathrm{L}-2,4$ diaminobutyric acid (DAB). J Neurooncol. 2006;80(3):285-93. https://doi.org/ 10.1007/s11060-006-9186-1.

81. Jain RK, di Tomaso E, Duda DG, Loeffler JS, Sorensen AG, Batchelor TT. Angiogenesis in brain tumours. Nat Rev Neurosci. 2007;8(8):610-22. https://doi.org/10.1038/nrn2175.

82. Adson A, Raub TJ, Burton PS, Barsuhn CL, Hilgers AR, Audus $\mathrm{KL}$, et al. Quantitative approaches to delineate paracellular diffusion in cultured epithelial cell monolayers. J Pharm Sci. 1994;83(11):1529-36. https://doi.org/10.1002/jps.2600831103.

83. Avdeef A. How well can in vitro brain microcapillary endothelial cell models predict rodent in vivo blood-brain barrier permeability? Eur J Pharm Sci. 2011;43(3):109-24. https://doi.org/10. 1016/j.ejps.2011.04.001.

84. Ho NFH, Raub TJ, Burton PS, Barsuhn CL, Adson A, Audus $\mathrm{KL}$, et al. Quantitative approaches to delineate passive transport mechanisms in cell culture monolayers. In: Amidon, G.L., Lee, P.I., Topp, E.M., editors. Transport Processes in Pharmaceutical Systems. New York, NY, 2000; pp 219-316.

85. Fattori S, Becherini F, Cianfriglia M, Parenti G, Romanini A, Castagna M. Human brain tumors: multidrug-resistance P-glycoprotein expression in tumor cells and intratumoral capillary endothelial cells. Virchows Arch. 2007;451(1):81-7. https://doi. org/10.1007/s00428-007-0401-z.

86. Kil WJ, Cerna D, Burgan WE, Beam K, Carter D, Steeg PS, et al. In vitro and in vivo radiosensitization induced by the DNA methylating agent temozolomide. Clin Cancer Res. 2008;14(3):931-8. https://doi.org/10.1158/1078-0432.CCR-07-1856.

87. Park SH, Kim MJ, Jung HH, Chang WS, Choi HS, Rachmilevitch I, et al. One-year outcome of multiple blood-brain barrier disruptions with temozolomide for the treatment of glioblastoma. Front Oncol. 2020;10:1663. https://doi.org/10.3389/fonc.2020.01663.

88. Singh N, Miner A, Hennis L, Mittal S. Mechanisms of temozolomide resistance in glioblastoma - a comprehensive review. Cancer Drug Resist. 2021;4:17-43. https://doi.org/10.20517/cdr. 2020.79

89. Avdeef A. Re: What is the permeability of temozolomide across the blood-brain barrier? 2019. https://www.researchgate.net/ post/What_is_the_permeability_of_temozolomide_across_the_ blood-brain_barrier/5c3f3e1a11ec737af3403d2a/citation/downl oad. Accessed 8 Sep 2021.

90. Miyajima M, Kusuhara H, Takahashi K, Takashima T, Hosoya $\mathrm{T}$, Watanabe Y, et al. Investigation of the effect of active efflux at the blood-brain barrier on the distribution of nonsteroidal aromatase inhibitors in the central nervous system. J Pharm Sci. 2013;102(9):3309-19. https://doi.org/10.1002/jps.23600.

91. Bronger H, König J, Kopplow K, Steiner HH, Ahmadi R, HeroldMende $\mathrm{C}$, et al. ABCC drug efflux pumps and organic anion uptake transporters in human gliomas and the blood-tumor barrier. Cancer Res. 2005;65(24):11419-28. https://doi.org/10.1158/ 0008-5472.CAN-05-1271.

92. Schinkel AH. P-Glycoprotein, a gatekeeper in the blood-brain barrier. Adv Drug Deliv Rev. 1999;36(2-3):179-94. https://doi. org/10.1016/s0169-409x(98)00085-4.

93. Sane R, Wu SP, Zhang R, Gallo JM. The effect of ABCG2 and $\mathrm{ABCC} 4$ on the pharmacokinetics of methotrexate in the brain. Drug Metab Dispos. 2014;42(4):537-40. https://doi.org/10.1124/ dmd.113.055228.

94. Li L, Agarwal S, Elmquist WF. Brain efflux index to investigate the influence of active efflux on brain distribution of pemetrexed and methotrexate. Drug Metab Dispos. 2013;41(3):659-67. https://doi.org/10.1124/dmd.112.049254.

95. Kanamitsu K, Kusuhara H, Schuetz JD, Takeuchi K, Sugiyama $\mathrm{Y}$. Investigation of the importance of multidrug resistance-associated protein 4 (Mrp4/Abcc4) in the active efflux of anionic drugs across the blood-brain barrier. J Pharm Sci. 2017;106(9):256675. https://doi.org/10.1016/j.xphs.2017.04.040.

96. VanWert AL, Sweet DH. Impaired clearance of methotrexate in organic anion transporter 3 (Slc22a8) knockout mice: a gender specific impact of reduced folates. Pharm Res. 2008;25(2):45362. https://doi.org/10.1007/s11095-007-9407-0.

97. Trapa PE, Troutman MD, Lau TY, Wager TT, Maurer TS, Patel $\mathrm{NC}$, et al. In vitro-in vivo extrapolation of key transporter activity at the blood-brain barrier. Drug Metab Dispos. 2019;47(4):40511. https://doi.org/10.1124/dmd.118.083279.

98. Storelli F, Anoshchenko O, Unadkat JD. Successful prediction of human steady-state unbound brain-to-plasma concentration ratio of P-gp substrates using the proteomics-informed relative expression factor approach. Clin Pharmacol Ther. 2021;110(2):432-42. https://doi.org/10.1002/cpt.2227.

99. Li J, Jiang J, Wu J, Bao X, Sanai N. Physiologically based pharmacokinetic modeling of central nervous system pharmacokinetics of CDK4/6 inhibitors to guide selection of drug and dosing regimen for brain cancer treatment. Clin Pharmacol Ther. 2021;109(2):494-506. https://doi.org/10.1002/cpt.2021.

100. Gerstner ER, Fine RL. Increased permeability of the blood-brain barrier to chemotherapy in metastatic brain tumors: establishing a treatment paradigm. J Clin Oncol. 2007;25(16):2306-12. https://doi.org/10.1200/JCO.2006.10.0677.

101. Mohammad AS, Adkins CE, Shah N, Aljammal R, Griffith JIG, Tallman RM, et al. Permeability changes and effect of chemotherapy in brain adjacent to tumor in an experimental model of metastatic brain tumor from breast cancer. BMC Cancer. 2018;18(1):1225. https://doi.org/10.1186/s12885-018-5115-x.

102. Liu LJ, Brown SL, Ewing JR, Ala BD, Schneider KM, Schlesinger M. Estimation of Tumor Interstitial Fluid Pressure (TIFP) noninvasively. PLoS ONE. 2016;11(7):e0140892. https://doi.org/ 10.1371/journal.pone.0140892.

103. Kingsmore KM, Vaccari A, Abler D, Cui SX, Epstein FH, Rockne RC, et al. MRI analysis to map interstitial flow in the brain tumor microenvironment. APL Bioeng. 2018;2(3):031905. https://doi.org/10.1063/1.5023503.

104. Zhan W, Alamer M, Xu XY. Computational modelling of drug delivery to solid tumour: Understanding the interplay between 
chemotherapeutics and biological system for optimised delivery systems. Adv Drug Deliv Rev. 2018;132:81-103. https://doi.org/ 10.1016/j.addr.2018.07.013.

105. Linninger A, Hartung GA, Liu BP, Mirkov S, Tangen K, Lukas $\mathrm{RV}$, et al. Modeling the diffusion of D-2-hydroxyglutarate from IDH1 mutant gliomas in the central nervous system. Neuro Oncol. 2018;20(9):1197-206. https://doi.org/10.1093/neuonc/noy051.
106. Vendel E, Rottschäfer V, de Lange ECM. The 3D brain unit network model to study spatial brain drug exposure under healthy and pathological conditions. Pharm Res. 2020;37(7):137. https:// doi.org/10.1007/s11095-020-2760-y.

Publisher's Note Springer Nature remains neutral with regard to jurisdictional claims in published maps and institutional affiliations. 